\title{
Nitrogen compounds removal from oil-derived middle distillates by MIL-101(Cr) and its impact on ULSD production by hydrotreating
}

Edith Meneses-Ruiz ${ }^{1}$ (D), José Escobar ${ }^{1, *}$, Rodolfo Juventino Mora ${ }^{1}$, José Ascención Montoya ${ }^{1}$ (D), María Concepción Barrera ${ }^{2}$, Dora Solís-Casados ${ }^{3}$, Luis Escobar-Alarcón ${ }^{4}$ (D), Paz Del Ángel ${ }^{1}$, and Georgina Laredo ${ }^{1}$ (1)

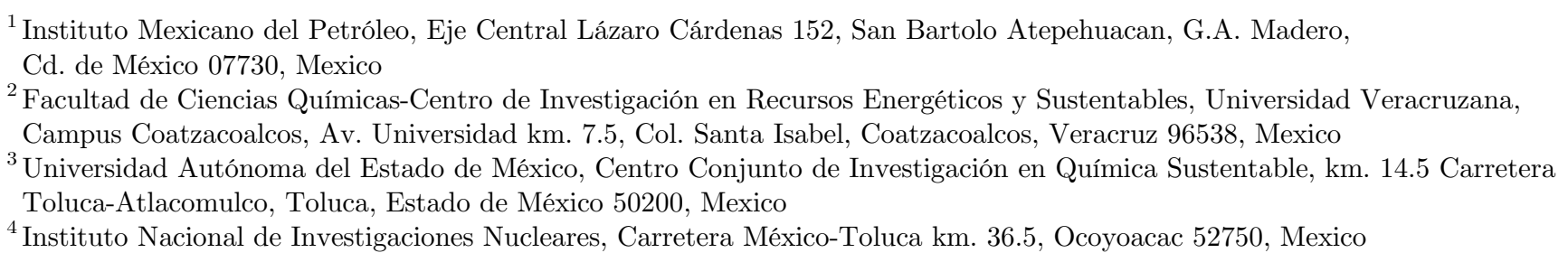

Received: 5 February 2021 / Accepted: 22 June 2021

\begin{abstract}
Oil-derived middle distillates (straight-run gas oil and mixture with light cycle oil and coker gas oil) for Ultra-Low Sulfur Diesel (ULSD) production by HyDroTreating (HDT) were pretreated by selective Nitrogen Organic Compounds (NOC) adsorption. Highly crystalline Metal-Organic Framework (MOF) MIL-101(Cr) prepared with propylene oxide (proton scavenger) as textural improver was used to that end. MOF was characterized by $\mathrm{N}_{2}$ physisorption, X-ray diffraction, thermal analysis, infrared, Raman and UV-vis spectroscopies, and electron microscopy (SEM and HR-TEM). NOC removal was carried out at room temperature and atmospheric pressure, the adsorbent being easily regenerable under mild conditions. Extruded MOF efficiently removed NOC from real feedstocks to concentrations $\sim 80 \mathrm{ppm}$ which allowed ULSD production at much milder conditions to those used during pristine feedstocks HDT. Operating temperature could be significantly diminished (from 350 to $330{ }^{\circ} \mathrm{C}$, at $56 \mathrm{~kg} \mathrm{~cm}^{-2}\left(5.77 \mathrm{MPa}\right.$ ), LHSV $=1.5 \mathrm{~h}^{-1}, \mathrm{H}_{2} / \mathrm{oil}=2500 \mathrm{ft}^{3} \mathrm{bbl}^{-1}$ $\left(445 \mathrm{~m}^{3} \mathrm{~m}^{-3}\right)$ ) which could notably prolong cycle life of $\mathrm{NiMo} / \mathrm{Al}_{2} \mathrm{O}_{3}$ formulation used.
\end{abstract}

\section{Introduction}

Ever stricter environmental regulations demand for UltraLow Sulfur Diesel (ULSD, 10-15 ppm S) from oil-derived middle distillates HyDroTreating (HDT). Those legislations mandate diminishing at the highest possible extent the deleterious effect of $\mathrm{SO}_{\mathrm{X}}, \mathrm{NO}_{\mathrm{X}}$, soot, etc., in exhaust gases from compression ignition engines. High-S diesel usage could rapidly poison catalytic phases in both DPF (Diesel Particulate Filters) and SCR (Selective Catalytic Reduction) devices used to relieve soot and $\mathrm{NO}_{\mathrm{x}}$ production, respectively [1]. Producing ULSD typically requires of sulfur removal as high as $99.9 \mathrm{wt} \%$ through HydroDeSulfurization (HDS). Corresponding HDT process conditions are very demanding as elimination of very refractory $\mathrm{S}$ species (sterically hindered alkyl-DiBenzoThiophenes (alky-DBT) [2] constituting the last ppm of sulfur to be removed) is

\footnotetext{
* Corresponding author: jeaguila@imp.mx
}

required. Nitrogen Organic Compounds (NOC) in middle distillates feedstocks for ULSD production are wellknown inhibitors of desulfurizating/dehydrogenating functionalities of sulfided alumina-supported CoMo or NiMo formulations loaded in industrial hydrotreaters that deleterious effect depending upon their concentration $(\sim 250-1000 \mathrm{ppm} \mathrm{N})$ and type [3-5]. Basic N-bearing species (QUInoline (QUI), acridine, etc.) could be stronger HDS inhibitors that non-basic ones (INDole (IND), CarBaZole (CBZ), etc.), even though the latter could be converted to the former by hydrogenation under HDT conditions [4]. Strong NOC adsorption on active sites [5] could preferably affect hydrogenating properties of CoMo or NiMo formulations. That results specially harmful considering that the most refractory S-species in middle distillates could be preferably removed through HYDrogenation (HYD) route (instead of by the Direct DeSulfurization one, DDS) [2]. Strongly adsorbed QUI could also significantly decrease saturating capabilities of metallic $\mathrm{Ni} / \gamma$-alumina applied in 
diolefins saturation [6]. To offset strong HDT reactions inhibition by NOC, industrial hydrotreaters have to operate under severe conditions (temperature, pressure, LHSV, etc.) that resulting in shortened catalysts life cycle. Also, Liquid Hourly Space Velocity (LHSV) could be decreased (to augment feedstock-catalyst contact time) [7] but the ULSD volumetric production could be then diminished. In financially constrained commercial units operating at mid pressure $\left(<30-40 \mathrm{~kg} \mathrm{~cm}^{-2}(<3.14-4.15 \mathrm{MPa})\right)$ where revamps to improve HDS conversion could not be affordable Straight-Run Gas Oil (SRGO) streams are commonly diluted with lighter fractions (kerosene, for instance [8]) to enable ULSD production. On the other hand, by increasing HDT severity (operating at higher pressure, over $70 \mathrm{~kg}$ $\mathrm{cm}^{-2}$ (7.19 MPa), for example) could enable integration of other more difficult low-priced feedstocks available in refineries. In this context, Light Cycle Oil (LCO) [9] and/or coker gas oil CGO [10] could be utilized improving ULSD production and leading to enhanced revenues. However, integration of cracked feedstocks could be challenging due to their higher NOC content as to that in SRGO, particularly in CGO [10]. Obtaining fuel of very low $\mathrm{S}$ content $(\leq 15 \mathrm{ppm})$ could not be possible as N-bearing species are still present in the reactor effluent. Thus, total elimination of those compounds (commonly through HydroDeNitrogenation, HDN) is sine qua non condition for ULSD production $[3,5]$. By traditional HDT, that could imply increased consumption of expensive hydrogen as aromatics ring pre-hydrogenation is mandatory (with consequential carbon hybridization change from $s p^{2}$ to $s p^{3}$ ) prior to heterocyclic $\mathrm{C}-\mathrm{N}$ bond breaking [11]. Even more, the $\mathrm{NH}_{3}$ byproduct formed could itself inhibit catalytic active sites although its influence is not as strong as to that of heterocyclic N-species due to its weaker adsorption [12].

Improved catalytic formulations of enhanced HDS and HDN activity through modification of supports [13-15] and active phases including noble metals $[14,15]$ have been proposed to deal with distillates (feedstocks for ULSD production) derived from heavy oil of high $\mathrm{N}$ and $\mathrm{S}$ content, as lighter petroleum reservoirs become depleted.

One different strategy to relief mentioned constraints consists in diminishing NOC content in feedstocks to HDT through their removal using efficient solid adsorbents. Numerous materials have been proposed to that end, ranging from zeolites [16], acid ion-exchange resins [9], and carbon-based solids [17, 18], among others. However, economical feasibility of adsorptive NOC elimination from middle distillates is strongly dependent upon the extent of heteroatoms removal, adsorbent cost and regenerability and process conditions used (temperature, pressure, LHSV, etc.). Metal-Organic Frameworks (MOF) possess remarkable physicochemical properties [19] than make them attractive as catalysts [20, 21] and adsorbents [22, 23]. Those extremely porous organic-inorganic frameworks consist of well-defined structures where metal cations form nodes meanwhile organic moieties constitute linkers between metallic centers. Those polymeric networks are constructed through coordinative bonds [23]. The MIL101(Cr) (MIL, Material Institut Lavoisier) comprises trimeric chromium (III) octahedral clusters interconnected by 1,4-benzenedicarboxylate ligands conforming extremely porous 3-dimentional structure [24]. That MOF has shown very interesting properties as adsorbent $[25,26]$ and catalysts [27, 28]. Regarding N-species removal that nanostructured material either functionalized $[29,30]$ or not $[31,32]$ has shown significant selectivity to those compounds over S-bearing ones [31, 32]. Also, phytic acid- functionalized MIL-101(Cr) has also shown preferred NOC adsorption over that of aromatics [29]. Very large surface area of non-functionalized nano-structured MIL-101(Cr) provides plenty of adsorption sites located on the carbon atoms of carboxylic groups of 1,4-BenzeneDiCarboxylate (BDC) units or on the coordinatively unsaturated sites (CUS) formed on $\mathrm{Cr}^{3+}$ cations by water molecules removal [33]. According to Pearson's hard/soft acid/base concepts [34] N-bearing basic compounds are intermediate to strong bases while S-bearing species could be intermediate to soft ones [32]. Thus, a hard base (as QUI) preferably interacts with a hard Lewis acid site (as $\mathrm{Fe}^{3+}, \mathrm{Cr}^{3+}$, or $\mathrm{Al}^{3+}$ ) and with intermediate Lewis sites as well. Conversely, softer $\mathrm{S}$-species could be prone to interact with intermediate or soft Lewis sites as those on $\mathrm{Cu}^{2+}, \mathrm{Zn}^{2+}, \mathrm{Co}^{2+}, \mathrm{Ni}^{2+}$, and $\mathrm{Cu}^{+}$[32]. MIL-101(Cr) has shown very superior properties as NOC adsorbent as to other solids [31, 35]. Considering NOC removal from SRGO and SRGO/LCO mixtures our group reported [35] that MIL-101(Cr) had 2.3 times higher adsorption capacity and corresponding adsorption rate at least twice faster to those of commercial adsorbents as Selexsorb $^{\circledR}$ CDX, Selexsorb ${ }^{\circledR}$ CD, SG silica gel and VG-077 activated carbon.

In spite of that, studies on testing MIL-101(Cr) in NOC removal from SRGO and other middle distillates of higher $\mathrm{N}$ content (LCO and CGO, for instance) are very scarce $[31,35]$. Even more, the effect of using the corresponding low-nitrogen streams (SRGO and mixtures with LCO and CGO) on ULSD production under operating conditions applicable in real-world commercial hydrotreaters have not been addressed, at the best of our knowledge. Some years ago SK Corporation (from South Korea) offered an innovative technology that could enable ULSD production in low to medium pressure industrial hydrotreaters processing middle distillates $[36,37]$. Proprietary adsorbent characteristics were not disclosed but NOC removal accompanied by elimination of other polar species (including refractory alky-DBT) were claimed to be responsible for significantly enhanced pretreated middle-distillates HDS. Even though very interesting results were presented $[36,37]$ no further updates were provided. Although some state-of-the-art commercial HDT catalysts are active enough to enable ULSD production in commercial hydrotreaters [38] there will always be room for improvements derived from operating at lower Start-Of-Run (SOR) temperature (actually, Weight Averaged Bed Temperature (WABT), representative of that of the catalytic bed under adiabatic conditions [39]) due to lengthened catalyst life cycle. Considering typical catalyst deactivation in commercial hydrotreaters of $\sim{ }^{\circ} \mathrm{C}$ month $^{-1}$ [40] (increase in temperature to keep isoconversion), diminishing $10{ }^{\circ} \mathrm{C}$ in SOR temperature could represent 10 months longer cycle. For a 30000 barrels day $^{-1}\left(5.52 \times 10^{-2} \mathrm{~m}^{3} \mathrm{~s}^{-1}\right)$ hydrotreater that could mean 
extra $\sim 9 \times 10^{6}$ barrels $\left(1.431 \times 10^{6} \mathrm{~m}^{3}\right)$ ULSD produced before costly catalyst change.

In this contribution a detailed study using MIL-101(Cr) during pre-treatment of Straight-Run Gas Oil (SRGO) and mixture with Light Cycle Oil (LCO) and Coker Gas Oil (CGO) aimed to ULSD production by HyDroTreating (HDT) at commercially relevant conditions was carried out. MOF prepared with Propylene Oxide (PO) as proton scavenger was used to that end. In the first part of the paper, the adsorbent was characterized by several techniques to demonstrate that $\mathrm{PO}$ addition significantly contributed in enhancing solid matrix mesoporosity meanwhile maintaining essentially unaltered surface and structural properties of MIL-101(Cr). In the second part, the effect of NOC removal on ULSD production from aforementioned middle distillates HDT was addressed. NOC elimination was carried out at mild conditions (room temperature and atmospheric pressure), the adsorbent being easily regenerable. MOF shaped as extrudates was loaded in packed up-flow column during adsorption experiments. Efficient NOC removal from oil-derived real feedstocks to concentrations $\sim 80 \mathrm{ppm}$ (from around 300 to $400 \mathrm{ppm}$ in non-pretreated streams) enabled ULSD $(S \leq 15 \mathrm{ppm})$ production at much milder operating conditions as to those used during pristine feedstocks HDT over a commercial $\mathrm{NiMo} / \mathrm{Al}_{2} \mathrm{O}_{3}$ sulfided formulation.

\section{Experimental}

\subsection{Adsorbent synthesis}

Reactants used to synthesize MOF MIL-101(Cr) by hydrothermal method were (all from Aldrich) $\mathrm{Cr}(\mathrm{NO})_{3} \cdot 9 \mathrm{H}_{2} \mathrm{O}$ ( $\geq 98 \mathrm{wt} \%)$, terephthalic acid $\left(\mathrm{H}_{2} \mathrm{BDC}, 98 \mathrm{wt} \%\right)$, and Propylene Oxide (PO, $\geq 99 \mathrm{wt} \%) .660 \times 10^{-6} \mathrm{~m}^{3}$ of bi-distillated $\mathrm{H}_{2} \mathrm{O}$ were kept under vigorous stirring (at room temperature, for $600 \mathrm{~s}$ ). $22.174 \mathrm{~g}$ of $\mathrm{H}_{2} \mathrm{BDC}$ were then added continuing the stirring for 600 more seconds. To improve $\mathrm{H}_{2} \mathrm{BDC}$ dissolution ultrasounds pulses (SONICS Vibra$\mathrm{Cell}^{\mathrm{TM}}, 80 \%$ output power, during $360 \mathrm{~s}$ ) were applied. Then, $52.879 \mathrm{~g}$ of $\mathrm{Cr}(\mathrm{NO})_{3} \cdot 9 \mathrm{H}_{2} \mathrm{O}$ were introduced the resulting mixture being stirred for 1200 more seconds. Finally, $4.11 \mathrm{~g}$ of $\mathrm{PO}$ were added stirring being kept for 600 more seconds. The resulting mixture was put in polytetrafluoroethylenelined stainless steel vessel which was then air-tight closed. Hydrothermal treatment was carried out by $24 \mathrm{~h}$ at $180{ }^{\circ} \mathrm{C}, 200 \mathrm{rpm}\left(21 \mathrm{rad} \mathrm{s}^{-1}\right)$ stirring rate and autogenous pressure. The obtained suspension was then filtered and washed (twice) with acetone to remove unreacted $\mathrm{H}_{2} \mathrm{BDC}$. The precipitated solid was dried at $120^{\circ} \mathrm{C}, 18 \mathrm{~h}$.

\subsection{Extruded adsorbent preparation}

At our best knowledge, shaping MIL-101(Cr) as extrudates to be used as $\mathrm{N}$-species adsorbent has only been reported from our group [35, 41]. However, corresponding monoliths have been used as efficient $\mathrm{CO}_{2}$ adsorbents [42, 43]. Most of the NOC adsorption studies so far reported have been carried by utilizing powders or granulates that could hardly have practical real-world application due to high pressure

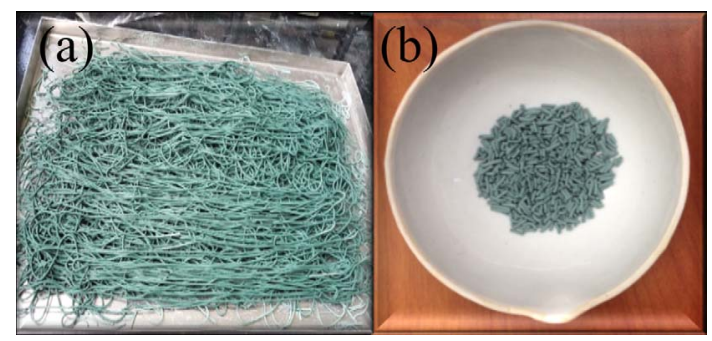

Fig. 1. MOF MIL-101(Cr) extrudates. (a) As-prepared; (b) cut, $1 / 16$ inch $\left(1.58 \times 10^{-3} \mathrm{~m}\right) \times 2-3 \times 10^{-3} \mathrm{~m}($ diameter $\times$ length $)$.

drop that could be caused in packed adsorption systems. Also, extrusion was preferred over spherical particles of similar dimensions could provoke enhanced pressure drop in the column. Thus, MOF was shaped as cylindrical particles of $\sim 1.6 \mathrm{~mm}$ diameter and $2-3 \mathrm{~mm}$ length. To that end, MIL-101(Cr) was mixed with CarboxyMethyl Cellulose (CMC, $5 \mathrm{wt} \%)$ and water was added to powders mixture which was then kneaded. Nitric acid aqueous solution (5 wt\%) was added as peptizer. Additional water was added until getting paste with suitable consistency for feeding extruder provided with $1 / 16$ inch hole spinneret. Obtained extrudates (Fig. 1a) were dried at $120^{\circ} \mathrm{C}(24 \mathrm{~h})$, then cut to 2-3 mm length (Fig. 1b).

\subsection{Adsorbent characterization}

Textural properties of MOF-MIL-101(Cr) (powder and extruded) were determined by $\mathrm{N}_{2}$ physisorption (at $-198{ }^{\circ} \mathrm{C}, \mathrm{N}_{2}$ saturation temperature at $78 \mathrm{kPa}$, atmospheric pressure in Mexico City) in Micromeritics Tristar II 3020 apparatus after ultra-high vacuum degassing at $\sim 150{ }^{\circ} \mathrm{C}$ (to prevent any damage to MOF structure) for $2 \mathrm{~h}$. Surface area and pore size distribution of studied materials were determined by BET and BJH (adsorption branch data) methods, respectively.

MOF structural order was studied by X-ray diffraction with a $\mathrm{D} 8$ discover apparatus from Bruker by using $\mathrm{Cu}_{\mathrm{Ka}}$ radiation, $\lambda=0.15406 \mathrm{~nm}$, in the $0-20^{\circ} 2 \theta$ range.

ThermoGravimetric Analysis (TGA) of extruded adsorbent was carried out through a TA instruments Q2000 equipment. 15-50 mg sample was analyzed in the $30-$ $1000^{\circ} \mathrm{C}$ temperature range (heating ramp of $0.166^{\circ} \mathrm{C} \mathrm{s}^{-1}$ ). Differential ThermoGravimetric (DTG) profile was obtained through derivative of corresponding TG curve.

FTIR (Fourier-Transform InfraRed) spectrum of extruded MOF was acquired by using Perkin Elmer Frontier FT-IR equipment with an attached Praying Mantis Diffuse Reflection Accessory, in the 4000-500 $\mathrm{cm}^{-1}$ range.

UV-vis Diffuse Reflectance Spectroscopy (DRS) analysis of extruded adsorbent was carried out in Perkin Elmer Lambda 35 spectrophotometer equipped with integration sphere. Spectra were acquired in the 200-1100 nm wavelength range. Spectralon signal was subtracted as baseline. Extruded MOF was also studied by MicroRaman Spectroscopy using an HR LabRam800 equipment coupled with Olympus BX40 confocal microscope. A Nd:YAG $532 \mathrm{~nm}$ wavelength laser beam was focused by $50 \times$ microscope 
Table 1. Properties of used oil-derived middle distillates from Mexican refineries.

\begin{tabular}{lcccccc}
\hline Property & ASTM method & SRGO1 & SRGO2 & LCO & CGO & SR1LC \\
\hline API gravity $\left({ }^{\circ}\right)$ & D-287-12 & 33.4 & 33.12 & 13.4 & 34.78 & 28.77 \\
IBP $/$ FBP $\left({ }^{\circ} \mathrm{C}\right)$ & D-86-12 & $255.3 / 358.2$ & $161.1 / 360.8$ & $213 / 352.1$ & $182.6 / 323.1$ & $219.3 / 344.9$ \\
Cetane index & D-976-06 & 50.92 & 50.3 & 19.9 & 42.71 & 42.05 \\
S (wt\%) & D-4294-98 & 1.279 & 2.03 & 2.487 & 2.088 & 1.811 \\
N (ppm) & D-4629-08 & 220 & 410 & 335 & 507 & 300 \\
Aromatics (wt\%) & D-5186-03 & 29.8 & 34.1 & 84.2 & 36.4 & 44.9 \\
Mono- & & 18.5 & 20.6 & 17.6 & 20.8 & 18.8 \\
Di- & & 7.9 & 10.9 & 58.9 & 12.2 & 21.7 \\
Tri- & & 3.4 & 2.6 & 7.7 & 3.4 & 4.4 \\
Aliphatics $(w t \%) ~$ & & 60.2 & 65.9 & 15.8 & 63.6 & 55.1 \\
\hline
\end{tabular}

${ }^{a}$ By total hydrocarbons-aromatics difference.

objective with spot diameter close to $1 \mu \mathrm{m}$ onto the sample surface. To avoid sample heating then structural changes, laser power $(5 \mathrm{~mW})$ was regulated by a neutral density filter. Spectrum was calibrated using $521 \mathrm{~cm}^{-1}$ line of silicon wafer acquired in the $200-1800 \mathrm{~cm}^{-1}$ range $\left(1 \mathrm{~cm}^{-1}\right.$ resolution). A CCD camera was used to record the spectra, usually averaged from 100 accumulations in order to improve signal/noise ratio.

MOF MIL-101(Cr) morphological characterization was carried out by Scanning Electron Microcopy (SEM, Nova-200 Nanolab) and also by high-resolution transmission electron microscopy (HR-TEM, TITAN 80-300). As MIL-101(Cr) could be very sensitive to the electron beam power, HR-TEM images could be obtained at $300 \mathrm{kV}$ (accelerating voltage) by fine-tuning low-dosing the electron beam interacting with MOF nanostructures.

\subsection{Nitrogen compounds removal procedure}

Oil-derived middle distillates (SRGO1, SRGO2, LCO and CGO) were obtained from Mexican refineries (Tab. 1). A SRGO1/LCO/CGO mixture was prepared in 60/25/15 mass proportion (SR1LC from here on). NOC were partially removed by adsorption from those hydrocarbon streams in up-flow column (316 stainless steel, $2.54 \mathrm{~cm}$ diameter, $43 \mathrm{~cm}$ bed length) packed with $215 \times 10^{-6} \mathrm{~m}^{3}$ MOF extrudates (see Fig. S1) weighing $35 \mathrm{~g}\left(0.16 \mathrm{~g} \mathrm{~cm}^{-3}\right.$ packed bed compact bulk density). Prior to NOC removal MOF was activated by heating $\left(120^{\circ} \mathrm{C}, 12 \mathrm{~h}\right.$, to eliminate moisture and adsorbed species) under $\mathrm{N}_{2}$ stream $\left(1 \times 10^{-6} \mathrm{~m}^{3} \mathrm{~s}^{-1}\right)$. The column was then cooled down to $25{ }^{\circ} \mathrm{C}$ to start with NOC elimination procedure. Used temperature was suitable due to exothermal NOC adsorption as tests at increased values resulted in diminished $\mathrm{N}$-species adsorption due to unfavored thermodynamics. The goal was producing streams of $\sim 80 \mathrm{ppm} \mathrm{N}$ as previous experiences (unpublished results) showed that was required in feedstocks to be hydrotreated to economically effective produce ULSD under operating conditions used in commercial facilities. Although streams of lower NOC concentration $(<80 \mathrm{ppm})$ could be hydrotreated at milder conditions to produce ULSD more frequent adsorbent regeneration could be then necessary rendering the operation economically unattractive.

The column was up-flow operated at room temperature and atmospheric pressure (78 $\mathrm{kPa}$ in Mexico City). LHSV used $\left(0.6-1.5 \mathrm{~h}^{-1}\right)$ depended on NOC concentration in feedstocks, focusing in obtaining $\sim 80 \mathrm{ppm}$ in treated product pool. Total nitrogen in streams was determined by chemiluminescence through Antek MultiTek apparatus. Low nitrogen feedstocks LNSR1, LNSR2 and LNSR1LC were thus obtained from corresponding pristine SRGO1, SRGO2 and SR1LC streams, respectively. After each adsorption test the packed bed was regenerated to re-establish its adsorption capacity. Adsorbed non-polar hydrocarbons were firstly eliminated by $n$-hexane washing (room temperature and atmospheric pressure). The used solvent was recovered from the drained mixture by distillation. Hydrocarbons (both hold-up and desorbed) were returned to feedstock drum. On the other hand, polar compounds (mainly NOC) were extracted by acetone washing $\left(30^{\circ} \mathrm{C}\right.$, atmospheric pressure). Again, the solvent was recovered by distillation. During both washings (removal of non-polar and polar species), significant boiling point differences among used solvents and treated feedstocks facilitated that operation. The stream where NOC were heavily concentrated ( 15 000-25 $000 \mathrm{ppm})$ was sent to final disposition. That fraction typically represented less than $1 \mathrm{wt} \%$ of the total treated feedstock, in order to limit hydrocarbon losses. Otherwise, the adsorptive process could be uneconomical. Operating at milder conditions during middle distillates HDT by using a less-inhibited catalyst due to low-nitrogen feedstocks could result in volume swell by aromatics hydrogenation [44] that compensating for aforementioned product lost. In addition, that highly concentrated NOC stream could probably be integrated as component of residue FCC (Fluid Catalytic Cracking) [45] or hydrocracking [46] feedstocks. Finally, the packed column was dried $\left(120^{\circ} \mathrm{C}\right)$ under $\mathrm{N}_{2}$ stream $\left(8.33 \times 10^{-5} \mathrm{~m}^{3} \mathrm{~s}^{-1}\right)$ after which it was considered fully regenerated and ready for the next NOC adsorption cycle. Previously published data from our group [35] consistently showed that the MOF used in $\mathrm{N}$-species removal from oil-derived middle distillates could be easily regenerated after around 300 cycles of operation 
preserving unaltered adsorptive capacity. Physicochemical properties of our MIL-101 $(\mathrm{Cr})$ could be then considered intact after numerous regeneration cycles. It is worth mentioning that extruded MOF capacity for NOC removal was lower to that achievable by using corresponding powdered material (unpublished results) but in this case excessive pressure drop in the column could render the operation impractical.

Considering scaling-up of the adsorption process the most probable configuration could comprise a "lead/lag" alternating operation where one packed column ("lead", packed with fresh MIL-101(Cr)) could be at service under NOC removal meanwhile the other ("lag") could be in standby. When the adsorbent in originally "lead" column become spent (after obtaining a given volume of hydrocarbon stream of $\sim 80 \mathrm{ppm} \mathrm{N}$ ) the pristine feedstock flow could be directed to the second column (originally "lag", now "lead") packed with fresh MOF adsorbent. Regeneration of the spent adsorbent in previously used column could take place then, the whole cycle being repeated over and over.

\subsection{Catalytic HDT of pristine and low-nitrogen real feedstocks}

Fixed-bed up-flow reactor HDT of SRGO1, SRGO2, and SR1LC and corresponding low-nitrogen feedstocks (LNSR1, LNSR2 and LNSR1LC, respectively) was carried out over commercial highly active (Type II) NiMo/alumina (sulfided through proprietary methodology specified by the manufacturer) formulation. No further catalyst properties could be disclosed due to confidentiality agreements. Feedstocks processing was carried out under operating conditions relevant to industrial hydrotreaters in Mexican refineries $\left(T=330-350{ }^{\circ} \mathrm{C}, P=56 \mathrm{~kg} \mathrm{~cm}^{-2}\right.$ (5.77 MPa), LHSV $=$ $\left.1.25-2.5 \mathrm{~h}^{-1}, \mathrm{H}_{2} / \mathrm{oil}=2500 \mathrm{ft}^{3} \mathrm{bbl}^{-1}\left(445 \mathrm{~m}^{3} \mathrm{~m}^{-3}\right)\right)$. A dual micro pilot plant from VINCI $^{\mathrm{TM}}$ technologies was used to that end. Catalyst extrudates were sieved at 16-20 US Standard mesh $\left(\sim 1.09 \times 10^{-3} \mathrm{~m}\right.$ average particle diameter $)$. Crushed catalyst particles bed $\left(7.5 \times 10^{-6} \mathrm{~m}^{3}\right)$ was loaded in an up-flow steady-state fixed-bed reactor [47] (316 stainless steel, $10 \mathrm{~mm}$ internal diameter, three heating sections $150 \mathrm{~mm}$ long each). Up-flow regime was preferred as in the small reactor utilized proper hydrodynamics to insure adequate trickle-bed operation (suitable bed length, back-mixing absence, rivulets elimination, etc., [47]) could be hardly achieved. Catalytic bed was diluted with $2.5 \times 10^{-6} \mathrm{~m}^{3}$ of $\mathrm{SiC}$ (US Standard mesh $>60$, particle diameter $\left.<2.5 \times 10^{-4} \mathrm{~m}\right)$, to improve reactor hydraulics and isothermicity (differently to catalyst particles $\mathrm{SiC}$ is very good heat conductor [47]). After proper catalyst sulfiding reactor operating conditions were brought to those of catalyst testing, relevant to industrial hydrotreaters in Mexican refineries aimed to ULSD production. LN streams were tested first to avoid active sites inhibition that could have occurred by strong NOC adsorption if pristine untreated SRGO had been firstly fed. Otherwise, several days under steady-state operating conditions could have been required to effectively desorb NOC from the used catalyst [48], prior to LN streams testing. Also, before testing mixtures containing cracked feedstocks (SR1LC and
LNSR1LC) the freshly sulfided catalysts were stabilized by hydrotreating LN SRGO feedstocks as direct contact of cracked streams with hyperactive sites on freshly sulfided formulations could induce premature coking (then, rapid catalyst deactivation). Sampling of hydrotreated products was carried out each $24 \mathrm{~h}$ until three consecutive analyses did not show appreciable differences in sulfur concentration. $\mathrm{H}_{2} \mathrm{~S}$ dissolved in hydrotreated products was stripped-off by bubbling $\mathrm{N}_{2}$ stream to avoid its influence on total $\mathrm{S}$ concentration analysis. Even more, hydrotreated liquid samples were washed with $\mathrm{NaOH}$ solution $\left(10 \mathrm{wt} \%\right.$ ) to assure $\mathrm{H}_{2} \mathrm{~S}$ removal by sodium sulfide formation (which remained in aqueous phase). Sulfur content in liquid samples was determined by Monochromatic Wavelength Dispersive X-Ray Fluorescence (WDXRF, Sindie 7039 analyzer). Also, sulfur analyzes were carried through ANTEK apparatus (Model 7000 B, method ASTM-D 5453-04), to corroborate WDXRF results obtained.

Kinetics of sulfur removal by hydrotreating was described by power law equation [49]:

$$
k_{\mathrm{HDS}}=\frac{1}{n-1}\left[\left(\frac{1}{S_{P}^{n-1}}\right)-\left(\frac{1}{S_{F}^{n-1}}\right)\right] \mathrm{LHSV},
$$

where,

$k_{\mathrm{HDS}}$ : apparent HDS kinetic constant $\left(\mathrm{ppm} \mathrm{S}^{1-n} \mathrm{~h}^{-1}\right)$, $n$ : HDS reaction order,

$S_{P}:$ sulfur in product $(\mathrm{ppm})$,

$S_{F}$ : sulfur in feedstock (ppm),

LHSV: space velocity $\left(\mathrm{h}^{-1}\right)$.

HDS reaction order was determined from the best fit of experimental results tested for three $n$ values (namely 1.5, 1.75 and $2.0[5])$. $R$-squared (from linear regressions) was reliable statistical measure of data fitness, the closer to 1.0 , the better the fit.

\section{Results and discussion}

At the best of our knowledge using Propylene Oxide (PO) as proton scavenger during MOF MIL-101(Cr) synthesis has not been reported so far in the open literature [50]. Detailed studies on the effect of PO concentration on MIL-101(Cr) properties could be found in our previous patent [50]. That epoxide could promote gelation in sol-gel alumina synthesis from inorganic salts also playing an important role on mesopores formation [51]. Weak bases as epoxides react with protons from $\mathrm{H}_{2} \mathrm{O}$ in coordination sphere of hydrated metal complexes [52] (as those from $\mathrm{Cr}^{3+}$ ) forming then $\mathrm{Cr}(\mathrm{OH})_{\mathrm{x}}$ clusters. PO could be firstly protonated then consumed through irreversible ring opening reactions. Then, nucleophilic attack on the epoxide ring leads to its opening. Those reactions could take place either by interacting with $\mathrm{NO}_{3}^{-}$anions enhancing hydrolysis or by consuming $\mathrm{H}_{2} \mathrm{O}$ formed during condensation which further promotes that step [51]. The sol viscosity progressively increases by converting monomers to dimers then to trimers and so on. Presumably, during PO-modified MOF synthesis $\mathrm{Cr}(\mathrm{OH})_{\mathrm{x}}$ clusters react with dicarboxylic acid moieties [50] 
generating rigid highly porous networks gradually evolving by gelation [53] producing well-crystallized MIL-101(Cr) structure as it will be shown.

\subsection{Adsorbent characterization}

\subsubsection{Textural properties}

The isotherm of prepared MOF (as powder, Fig. S2) was similar to those already reported for materials prepared with alike $\mathrm{H}_{2} \mathrm{O} / \mathrm{H}_{2} \mathrm{BDC}$ molar ratio (275) [54] where strong contribution from micropores (filled at $P / P_{0}<0.3$ ) was evidenced. However, in our case significant rise in adsorption at $P / P_{0} \sim 0.8$ accompanied by desorption branch hysteresis (absent in conventional MIL-101(Cr) [55]) pointed out to mesopores probably created by PO addition that promoted condensation reactions resulting in agglomerated particles. Thus, significant mesopores (filled at $P / P_{0}>0.3$ ) contribution (33\% of total pore volume) was evidenced (Fig. S2). In this line, others [55] found corresponding rising in isotherms and hysteresis in MIL-101(Cr) solids prepared with cetyltrimethylammonium bromide as supramolecular template. Pore size distribution of prepared MOF (Fig. 2) included diameters in the micro-mesopores boundary as usually reported 1.4 [20]-2.2 $\mathrm{nm}$ [55] and additional mesopores maximum at $\sim 20 \mathrm{~nm}$ that according to Kelvin equation nicely corresponded to observed desorption branch hysteresis (pores filled at $P P_{0}^{-1} \sim 0.9$, Fig. S2). Hierarchically structured mesoporosity in our MOF could contribute to improved accelerated kinetics during NOC adsorption. MIL-101(Cr) with mesopores over $20 \mathrm{~nm}$ appreciably improved Methylene Blue (MB) diffusion into the porous network [55]. Thus, the effect of alike pores could expectably be similar on NOC elimination (mainly QUI, IND and CBZ) of likewise kinetic diameter than $\mathrm{MB}(\sim 1 \mathrm{~nm})$. Although the surface area $\left(S_{\mathrm{BET}}\right)$ and pore volume $\left(V_{p}\right)$ of as-prepared MOF decreased after shaping as extrudates (26 and 29\%, respectively, Tab. 2), the corresponding values were still much larger as to those of other materials used in NOC removal [35]. Average pore size $\left(D_{p}\right)$ as determined assuming cylindrical pores was essentially unaffected by extrusion shaping (Tab. 2) whereas micropore volume diminished by $30 \%$.

\subsubsection{Structural characterization (by XRD)}

Intense well-defined peak at $1.84^{\circ}(2 \Theta)$ characteristic of long-range structured MIL-101(Cr) was evidenced in corresponding XRD pattern (Fig. S3). Additional diffraction peaks were in full agreement with cubic structure [27], those very well defined signals corresponding to MIL-101(Cr) as simulated by others [30]. Observed intense inflections pointed out to MOF of high long-range structural order. Thus, it appeared that MIL-101(Cr) crystallinity was not importantly affected by using $\mathrm{PO}$ as mesoporosity inductor during materials synthesis. Interestingly, the (111) peak at approximately $1.7^{\circ}(2 \Theta)$ unstable in moistened air (decreased intensity or disappearing) [54] has been related to water molecules removal (thus CUS formation) from $\mathrm{MOF}$ structure. As aforementioned, CUS on octahedral $\mathrm{Cr}^{3+}$ trimers formed by dehydration could strongly

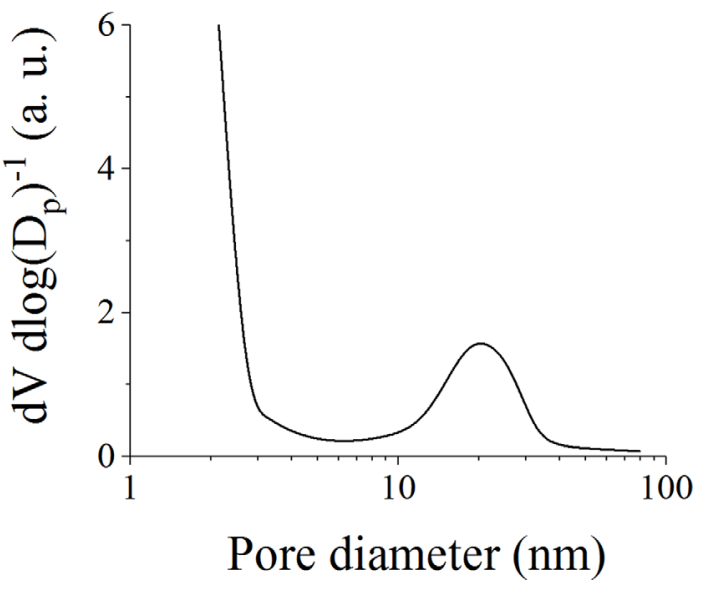

Fig. 2. Mesopore size distribution (BJH method, $\mathrm{N}_{2}$ adsorption branch data) of as-prepared MOF MIL-101(Cr).

contribute in NOC removal through their strong interaction with non-shared electron pairs in $\mathrm{N}$ moieties. MIL-101(Cr) structure was stable (as identified by (111) plane preservation) in presence of both polar and nonpolar solvents (as ethanol and benzene, respectively [54]) at corresponding boiling temperature what is relevant during regeneration process as the adsorbent is submitted to drying $\left(120^{\circ} \mathrm{C}\right)$ after acetone washing (see Sect. 2.4).

\subsubsection{Thermal analysis (TG-DTG)}

Significant weight loss $\left(\sim 27 \mathrm{wt} \%\right.$, Fig. S4a) up to $100{ }^{\circ} \mathrm{C}$ of MOF prepared was related to water evaporation from large cages which originated the first strong peak observed in corresponding DTG pattern (Fig. S4b). Indeed, MIL-101(Cr) is characterized by strong affinity to water molecules adsorption [56]. That suggested surface properties not importantly affected by epoxide addition during materials synthesis. High water adsorption capacity is desirable for the adsorbent as CUS on octahedral $\mathrm{Cr}^{3+}$ trimers formed by dehydration (during activation by drying, see Sect. 2.4) strongly contributes to NOC removal. Interestingly, our PO-modified adsorbent had significantly increased water elimination $(\sim 27 \mathrm{wt} \%)$ as to other MIL-101(Cr) materials prepared through other methods (7 and $13 \mathrm{wt} \%$ TGA loss in solids prepared with HF [56] or with neither HF nor solvent [57]).

Further losses in the $130-350{ }^{\circ} \mathrm{C}$ range have been related to hydroxyl groups [27] and coordinated water elimination. Also, evaporation of products from ring-opening of PO used during synthesis (1,2-propanediol and dipropylene glycol with boiling points of 187 and $232{ }^{\circ} \mathrm{C}$, respectively) could take place in this temperature interval [51] (see shoulder at $\sim 225{ }^{\circ} \mathrm{C}$ in DTG profile, Fig. S4b). Combustion of both carboxymethyl cellulose (CMC, used during extrudates shaping) and non-reacted terephthalate groups could also occur in aforementioned temperature range. Significant weight loss between 350 and $600{ }^{\circ} \mathrm{C}$ (maxima in DTG profile at 375 and $418{ }^{\circ} \mathrm{C}$ ) could be due to oxidation of both terephthalate ligands (accompanied of structural collapse) and $\mathrm{Cr}^{3+}$ cations to $\mathrm{Cr}_{2} \mathrm{O}_{3}$ ashes [56]. Observed TG profile 
Table 2. Textural properties of MOF MIL-101(Cr) (as-prepared powder and extrudates) as determined by $\mathrm{N}_{2}$ physisorption $\left(-198^{\circ} \mathrm{C}\right)$.

\begin{tabular}{lcccc}
\hline Sample & $S_{g \text { BET }}\left(\mathrm{m}^{2} \mathrm{~g}^{-1}\right)$ & $V_{p}\left(\mathrm{~cm}^{3} \mathrm{~g}^{-1}\right)$ & ${ }^{\mathrm{a}} D_{p}(\mathrm{~nm})$ & ${ }^{\mathrm{b}} V_{\mu p}\left(\mathrm{~cm}^{3} \mathrm{~g}^{-1}\right)$ \\
\hline Powder & 2412 & 1.53 & 2.54 & 1.02 \\
Extrudate & 1780 & 1.09 & 2.45 & 0.71 \\
\hline
\end{tabular}

${ }^{\mathrm{a}}$ From $4 \times \mathrm{V}_{\mathrm{p}} \times S_{g \mathrm{BET}}{ }^{-1}$.

b Micropores volume.

was in agreement with those reported by others [56] although it comprised enhanced physisorbed water contribution and slightly increased weight losses due to PO and $\mathrm{CMC}$ (absent in previously reported formulations) byproducts evaporation/combustion. Interestingly, our MOF presented much better thermal stability as to other formulations prepared by solid-phase reaction of $\mathrm{H}_{2} \mathrm{BDC}$ and chromium nitrate nonahydrate without addition of either solvent or hydrofluoric acid [57] where structural collapse by terephthalate ligands combustion was observed between 300 and $350{ }^{\circ} \mathrm{C}$. Good thermal stability of our PO-modified MOF was relevant considering the regeneration procedures used (see Sect. 2.4), as required after NOC adsorption tests.

\subsubsection{Electronic spectroscopy (UV-vis) studies}

Bands at 271, 432, and $591 \mathrm{~nm}$ are characteristic of MIL-101(Cr) [54], Figure S5. UV absorption was due to $n \rightarrow \pi^{*}$ electron transfer from terephthalate ligands meanwhile those in visible region could be related to electron transfer in 3d orbitals. Due to oxidation state of $\mathrm{Cr}^{3+}$ electron shifts could occur in the $3 d^{3}$ orbital according to electron configuration $\left(1 s^{2} 2 s^{2} 2 p^{6} 3 s^{2} 3 p^{6} 3 d^{3}\right)$ of those cations. Those signals in the visible spectrum (at 432 and $591 \mathrm{~nm}$ ) corresponded to characteristic bands for octahedral $\left(\mathrm{O}_{\mathrm{h}}\right) \mathrm{Cr}^{3+}$ species in oxide-like ligand environment of $\mathrm{Cr}$ trimers [58]. The $\mathrm{t}_{2 \mathrm{~g}} \rightarrow \mathrm{t}_{2 \mathrm{~g}} \mathrm{e}_{\mathrm{g}}{ }^{1}$ transition, split into the ${ }^{4} \mathrm{~T}_{1 \mathrm{~g}} \leftarrow \mathrm{A}_{2 \mathrm{~g}}$ and the ${ }^{4} \mathrm{~T}_{2 \mathrm{~g}} \leftarrow{ }^{4} \mathrm{~A}_{2 \mathrm{~g}}$ ones, could be related to the mentioned bands of higher and lower energy, respectively [59]. Evidently, using PO as proton scavenger (mesoporosity inductor) did not affect the coordinative state of $\mathrm{Cr}^{3+}$ component.

\subsubsection{Infrared spectroscopy}

Wide absorption band centered at $3262 \mathrm{~cm}^{-1}$ (Fig. S6) could be related to stretching vibrations (v) of adsorbed $\mathrm{H}_{2} \mathrm{O}$ and various types of hydroxyl groups [60] as well. Also, peak at $1623 \mathrm{~cm}^{-1}$ could be originated by bending vibrations $(\delta)$ of undissociated $\mathrm{H}_{2} \mathrm{O}$. As already mentioned, those sites where $\mathrm{H}_{2} \mathrm{O}$ desorbed during dehydration originated CUS where NOC could be effectively retained. Absorption due to aromatic $\mathrm{C}=\mathrm{C}$ stretching vibrations was observed at $1510 \mathrm{~cm}^{-1}$ meanwhile the one at $1583 \mathrm{~cm}^{-1}$ corresponded to $v_{\text {as }}$ stretch of carboxylate groups [61]. The last could include contributions from $\mathrm{CMC}$ added during extrusion. Very intense band at $1397 \mathrm{~cm}^{-1}$ was related to symmetric vibrations (O-C-O) of dicarboxylates confirming those linkers in the MOF framework [27]. Observed

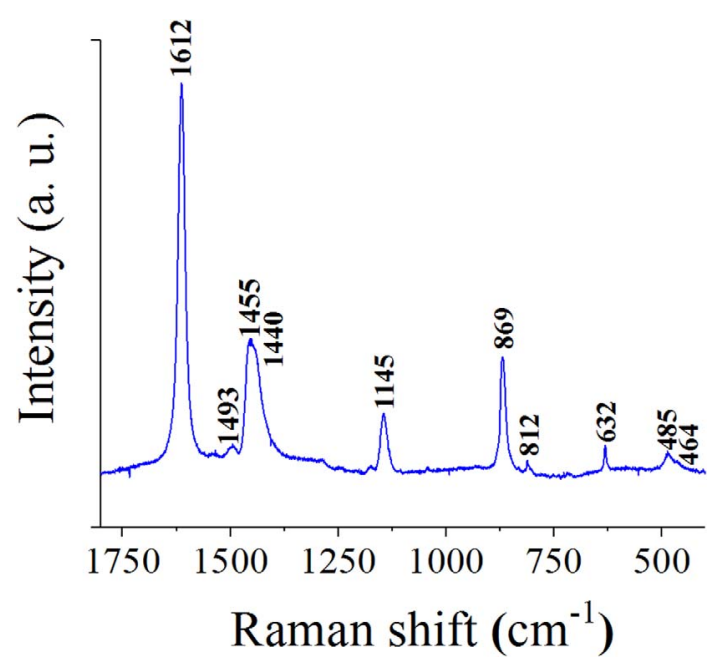

Fig. 3. Raman spectrum of extruded adsorbent MIL-101(Cr) prepared with propylene oxide.

vibrations from aromatic C-H deformations at 1160, 1018, 880 , and $750 \mathrm{~cm}^{-1}$ have been reported in the past for MIL-101(Cr) materials [62].

\subsubsection{Raman spectroscopy}

Raman signals at 1612,1455, 1145, 869 and $632 \mathrm{~cm}^{-1}$ (Fig. 3) were in full agreement to those reported in the past for MIL-101(Cr) [63]. Very sharp peaks observed strongly suggested well-ordered MOF. Several zones of MOF material were studied by Raman (Fig. S7) rather similar spectra being obtained that pointing out to homogeneous structure of PO-modified solid. Using that epoxide (proton scavenger) materials of improved porous network accessibility were obtained (by mesoporosity formation, Fig. 2) what could positively affect NOC diffusion, yet preserving high structural order at both short (as determined by Raman spectroscopy, Fig. 3) and long range (by XRD, Fig. S3).

\subsubsection{MOF morphological characterization by SEM\&HR-TEM}

SEM micrographs of extruded MOF at various magnifications are shown in Figure S8. Prepared extrudates contained plenty of void spaces convenient to improve NOC diffusion (Figs. S8a-S8b). At higher magnifications (Figs. S8c-S8d) faceted particles mainly in the 200-300 nm (average size: $223.6 \mathrm{~nm}$ ) range were evidenced. Spaces 


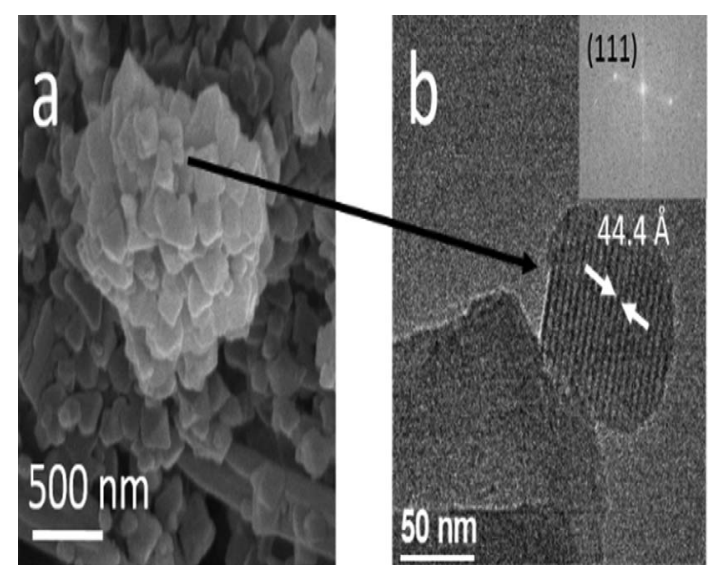

Fig. 4. (a) HR-TEM micrograph of extruded MOF material. (b) HR-TEM micrograph of MIL-101(Cr) crystal showing Fast Fourier Transform (FFT) analysis to determine (111) interplanar distance (i.e., $44.4 \AA)$. Inset: Selected Area Electron Diffraction Pattern of (111) plane.

among particles of similar size has been related to pores provoking hysteresis branch closing at $P P_{0}^{-1} \sim 0.85$ [64], similarly to our case (Fig. S2). Also, the observed hysteresis could be due to irregular shape of agglomerates originating pores of variable section. Octahedrally and cubooctahedrally shaped particles of double-side pyramidal geometry, typical of well crystallized MIL-101(Cr) [65-67], were observed by HR-TEM (Fig. 4). MOF particle size could be modulated by varying crystallization time [68]. Agglomerates composed by smaller particles aggregation were also observed (Fig. 4a). The 4.44 nm (111) interplanar distance (see Selected Area Electron Diffraction pattern, inset Fig. 4b), as determined by Fast Fourier Transform analysis (FFT, Fig. 4b), was in good agreement with that from XRD measurements (Fig. S3) through Bragg Law $(\sim 4.6 \mathrm{~nm})$. Those values were in accordance to that previously reported by others [54]. As already mentioned, that reflection could be related to planes where water molecules were removed (thus, formation of CUS where NOC could be adsorbed) by MOF structure [54].

Finally, MOF characterization through several techniques clearly evidenced that PO addition significantly contributed in obtaining well-crystallized MIL-101(Cr) of enhanced mesoporosity yet maintaining unaltered surface and structural properties.

\subsection{Nitrogen compounds removal}

NOC removal from various feedstocks was carried out until accumulated raffinate (LN, Low-Nitrogen streams) averaged $\sim 80 \mathrm{ppm} \mathrm{N}$ maximum. From previous studies, that was achieved by operating the MOF packed column (Fig. S1) until samples at $\sim 60$ wt $\% \mathrm{~N}$ removal were obtained. The process was then stopped, the adsorbent being then regenerated. Removed NOC amount from SR1LC mixture depended upon operating LHSV, Figure 5. At $0.6 \mathrm{~h}^{-1}$ space velocity and considering $100 \mathrm{bbl} \mathrm{ton}{ }^{-1}$ $\left(1.59 \times 10^{-2} \mathrm{~m}^{3} \mathrm{~kg}^{-1}\right)$ raffinate, $92 \mathrm{wt} \%$ of $\mathrm{N}$ could be eliminated whereas that amount diminished to $82 \mathrm{wt} \%$ when

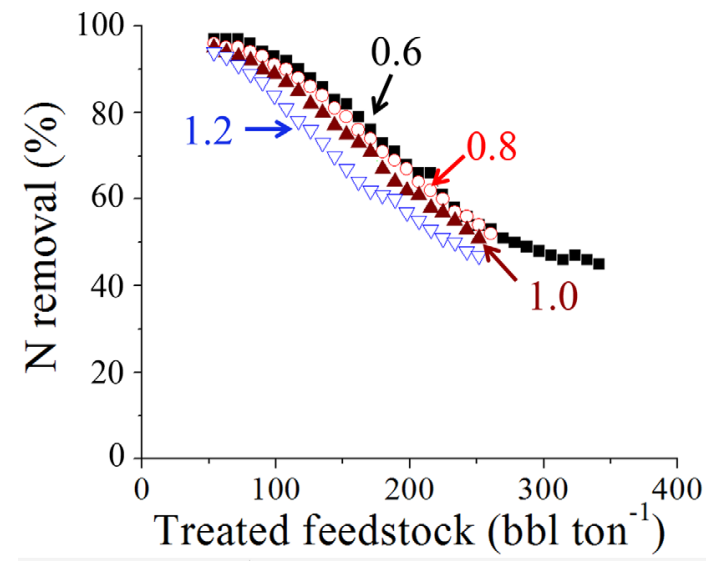

Fig. 5. Nitrogen removal (\%) versus raffinate volume per mass of adsorbent $\left(1 \mathrm{bbl} /\right.$ Ton $\left.=1.59 \times 10^{-4} \mathrm{~m}^{3} \mathrm{~kg}^{-1}\right)$, column packed with MIL-101(Cr). Effect of LHSV $\left(\mathrm{h}^{-1}\right)$. $\mathbf{\square}: 0.6$; O : 0.8; $\mathbf{\Delta}: 1.0$; $\nabla: 1.2$. SR1LC (mixture straight-run gas oil/light cycle oil/coker gas oil, $60 / 25 / 15 \mathrm{~m} / \mathrm{m})$ stream treated, atmospheric pressure $(78 \mathrm{kPa})$, room temperature $\left(25^{\circ} \mathrm{C}\right)$.

operating at $1.2 \mathrm{~h}^{-1}$. Thus, increased residence time of liquid hold-up in MOF bed was reflected in enhanced $\mathrm{N}$ removal. Note delayed NOC onset in experiments at lower LHSV in breakthrough curves (Fig. 5). However, that trend was not evident in corresponding curves from SRGO1 pretreatment at LHSV $=0.8,1.4$ and $2.0 \mathrm{~h}^{-1}$ (not shown), where NOC were not detected in the column effluent even at the lowest contact time feedstock-adsorbent probably due to their rapid adsorption, until raffinate volumes beyond $38 \mathrm{bbl} \mathrm{ton}{ }^{-1}\left(6.0 \times 10^{-3} \mathrm{~m}^{3} \mathrm{~kg}^{-1}\right)$. Thus, it seemed that slower NOC adsorption kinetics of more complex $\mathrm{N}$-species in the mixture containing cracked feedstocks (SR1LC) provoked the observed LHSV influence on NOC breakthrough (Fig. 5). That could imply the opportunity of improving even more the textural properties of our $\mathrm{PO}-$ modified MOF focusing in further mesopores enlargement (Fig. 2) aimed to accelerate heavier NOC diffusion. That could be probably achieved by augmenting the PO proportion during the MOF synthesis procedure [50]. High contents of non-basic NOC have been reported in Mexican LCO [69] what could make them less prone to be adsorbed due to mildly acidic MIL-101(Cr) surface [31, 32].

For a given NOC \% removal from SR1LC the accumulated raffinate volume augmented by decreasing operating LHSV (Fig. 5) as by increasing contact time more NOC could be retained on the adsorbent surface sites [70]. According to previous reports [35] total saturation of MIL-101(Cr) could be reached after treating 755 bbl ton ${ }^{-1}$ $\left(12 \times 10^{-2} \mathrm{~m}^{3} \mathrm{~kg}^{-1}\right)$ of SRGO/LCO (80/20 vol/vol, mixture originally containing $321 \mathrm{ppm} \mathrm{N})$, operating at $\mathrm{LHSV}=0.8 \mathrm{~h}^{-1}$. In our case, however, the raffinate volume was dictated by the maximum allowed $\mathrm{N}$ concentration in cumulated pools $(\sim 80 \mathrm{ppm})$. It is typically considered that around $\sim 80 \mathrm{wt} \%$ nitrogen removal from middle distillates is mandatory to allow ULSD production under operating conditions relevant to industrial hydrotreaters [3]. Regarding the SK HDS Pretreatment process [36] it was claimed that $90 \mathrm{wt} \%$ NOC removal from middle distillates was required 
to enable ULSD $(\leq 10 \mathrm{ppm}$ of $S$ ) production, under milder conditions to those used in the present work. When producing LNSR1LC at LHSV $=1.2 \mathrm{~h}^{-1}(\sim 60 \mathrm{wt} \% \mathrm{~N}$ removal) it was estimated that $4.2 \mathrm{mg}$ of $\mathrm{N} \mathrm{g}^{-1}$ of MOF were retained, lower amount to that reported at MIL-101(Cr) monolayer saturation when treating SRGO of $131 \mathrm{ppm} \mathrm{N}\left(9 \mathrm{mg} \mathrm{g}^{-1}\right.$, batch system [31]). Performance of an adsorbent depend not only upon its intrinsic equilibrium isotherm relating adsorbed species to bulk liquid concentration but also on the set-up (either batch or fixed-bed) in which the process is carried out [71]. In batch process the adsorbent could get in equilibrium with the remaining concentration in the bulk of fluid phase. This concentration could be significantly lower to that of the feedstock. On the other hand, in a fixed bed process feedstock is fed continuously through a packed adsorbent column that progressively gets fully loaded with adsorbate when in equilibrium with the feed concentration. Mass transfer phenomena could significantly limit the extent of adsorbent utilization. Also, powdered adsorbent is used in batch systems whereas shaped particles are loaded in continuous systems enhancing the influence of mass transfer control in the latter case. Indeed, during studies on NOC removal from straight-run gas oil higher adsorption capacity was found for MIL-101(Cr) when tests were carried out in batch systems, as opposed those realized in packed column [35].

The raffinate obtained at $\sim 60 \mathrm{wt} \% \quad \mathrm{~N}$ removal from SR1LC (300 ppm N in pristine mixture, Tab. 1) at LHSV $=0.8 \mathrm{~h}^{-1}, 225 \mathrm{bbl} \operatorname{ton}^{-1}\left(3.58 \times 10^{-2} \mathrm{~m}^{3} \mathrm{~kg}^{-1}\right)$ was higher to that previously reported [35] $\sim 157 \mathrm{bbl} \mathrm{ton}^{-1}$ $\left(2.49 \times 10^{-2} \mathrm{~m}^{3} \mathrm{~kg}^{-1}\right)$ at similar LHSV when treating SRGO/LCO (80/20 vol/vol, $321 \mathrm{ppm}$ in untreated mix). Discrepancies could be probably due to both distinctive textural and surface properties of MIL-101(Cr) materials prepared through unlike protocols and different compositions of tested hydrocarbons mixtures as well.

Hydrocarbon losses (high- $\mathrm{N}$ fraction recovered by regeneration through polar solvent) were $\sim 1 \mathrm{wt} \%$, lower to those reported for the SK Pretreatment process ( $2 \%$ of total treated stream) [36]. In the latter case, from total NOC retained by undisclosed adsorbents $\sim 50 \%$ were basic species (as QUI) the rest being non-basic ones (mainly IND and CBZ and alkyl derivatives) [36]). Also, other polar compounds were identified ( $S$ - and $O$-containing ones) and aromatics and saturated hydrocarbons as well, pointing out to non- selective adsorption.

The excellent capability of our MIL-101 (Cr) in NOC removal could be attributed to interaction through covalent coordinative bonds between nitrogen atoms (with un-shared electron pairs) and CUS formed by water removal (after adsorbent activation, see Sect. 2.4) [33] in $\mathrm{Cr}^{3+}$ trimers in octahedral coordination. In this line and from theoretical calculations [33] on those CUS basic PYridine (PY) could be strongly coordinated due to favorable thermodynamics. Also, NOC could be retained on carbon atoms of carboxylic groups of Benzene-1, interaction 4-DiCarboxylate (BDC) ligands [33] although NOC interaction with carbon atoms in BDC was not as strong as to that with CUS. Adsorption through aromatic rings $(\pi-\pi$ stacking interactions with terephthalate bridges [31]) could occur as well.

Very selective NOC adsorption over that of $S$-bearing species was evidenced, Table 3 . In all cases, $S$ removal was below $5 \mathrm{wt} \%$ whereas that of NOC was much higher (e.g., $83 \%$ in LNSR2). Others [31] found highly selective NOC adsorption (IND and CBZ) over that of dibenzothiophene (and corresponding alkylated derivatives) when using isooctane as solvent. That trend was enhanced when S-bearing species were in SRGO pointing out to competitive adsorption among dibenzothiophenes and aromatics (through $\pi-\pi$ stacking interactions with terephthalate ligands). In full agreement, S removal from the mixture containing aromatics-rich LCO (SR1LC) (Tab. 1) was lower as to that in corresponding SRGO1 pristine component (Tab. 3). By pretreating SRGO using MIL-101(Cr) prepared through different protocols (no PO addition) to that used in this work, $\sim 13 \mathrm{wt} \%$ total $\mathrm{S}$ removal was observed [72] at conditions at which $94 \mathrm{wt} \% \mathrm{~N}$ was retained by the adsorbent. Adsorption of sterically hindered S-species on MIL-101(Cr) [31] could contribute to ULSD production as they constitute the most resilient last parts per million of sulfur compounds to be eliminated. In this line, $15 \mathrm{wt} \%$ of sterically-hindered alkyl-dibenzothiophenes could be removed by MIL-101(Cr) from pristine SRGO containing $920 \mathrm{ppm}$ of those species [72]. Also, refractory S species elimination from SRGO during NOC adsorption (over undisclosed adsorbent) could significantly contribute to ULSD production when operating under commercially relevant HDT conditions $\left(\mathrm{CoMo} / \mathrm{Al}_{2} \mathrm{O}_{3}-\mathrm{NiMo} / \mathrm{Al}_{2} \mathrm{O}_{3}\right.$ stacked bed system) [3]. Similarly, under SK Pretreatment process operating conditions around $5 \mathrm{wt} \%$ of S was eliminated whereas 82 wt\% of $\mathrm{N}$ was removed by the multiadsorbent system used [37]. $\mathrm{N}$ content in pristine hydrocarbon feedstocks did not determine by itself the achievable NOC removal extent. That could be provoked by preferential adsorption of certain NOC types from different streams. MIL-101(Cr) has preference for basic N-species (as PY, QUI and their alkylderivatives) due to its rather weak acidic surface [33, 73]. In full agreement, SRGO denitrogenation (MIL-101(Cr) as adsorbent) at progressively lower $\mathrm{N}$ content (from 357 to $20 \mathrm{ppm}$ ) resulted in decreased basic/total nitrogen species ratio (from 0.29 to 0.1 ) due to preferential adsorption of the former [72]. Thus, it could be inferred that most of NOC remaining in LN hydrocarbon streams must be nonbasic ones, mainly IND (and alkyl-derivatives) and CBZ [3]. Basic NOC have much higher reactivity under hydrotreating conditions than non-basic species [3]. Thus, HDS inhibiting effects from remaining species after NOC removal could be mainly attributed to CBZ due to their strong adsorption on HDS catalysts active sites [3].

NOC in Mexican SRGO typically comprise QUI (and alkyl derivatives)/IND/CBZ (and alkyl derivatives) in $1 / 0.75 / 2.5$ mass ratio [69]. However, after preferential basic compounds removal by MIL-101(Cr) that proportion in LN streams could be significantly different as to that in pristine SRGO.

NOC in Mexican LCO included QUI (and alkyl derivatives)/IND/CBZ in $1 / 2.3 / 12.5$ mass ratio pointing out to 
Table 3. Sulfur and nitrogen content in real feedstocks submitted to adsorptive nitrogen species removal process in column packed with extruded MIL-101(Cr) (room temperature, atmospheric pressure $(78 \mathrm{kPa})$, LHSV $=1.5 \mathrm{~h}^{-1}$ ). Corresponding values for pristine streams included as reference.

\begin{tabular}{lcccccc}
\hline Component & SRGO1 & LNSR1 & SRGO2 & LNSR2 & SR1LC & LNSR1LC \\
\hline S (ppm) & 12790 & 12067 & 20300 & 19836 & 18110 & 17285 \\
S removal (\%) & & 5.65 & & 2.29 & & 4.56 \\
N (ppm) & 220 & 57 & 410 & 70 & 300 & 83 \\
N removal (\%) & & 74.09 & & 82.93 & & 72.33 \\
\hline
\end{tabular}

predominant non-basic compounds in much higher proportion than in SRGO, vide supra [69]. However, NOC in LCO could strongly depend upon type of FCC feedstock from which that stream was originated. Basic NOC in LCO were anilines and alkyl derivatives meanwhile non-basic were IND and CBZ from benzo- and dibenzo-CBZ disintegration under FCC conditions [74].

Regarding Coker Gas Oil (CGO), high proportion of basic NOC like PY (and alkyl derivatives) have been identified [75]. Indeed, basic species (PY, naphthenic PY and QUI) and CBZ (non-basic) have been found in CGO [76]. NOC removal could be enhanced by MIL-101(Cr) functionalized by graphite oxide $(0.25$ wt\%) as textural improver [77] (increased IND and QUI adsorption as linear function of enhanced surface area). Even more, when treating streams of high QUI concentration (as some CGO) acidic component addition (as aminomethanesulfonic acid at 2 mmol per gram of MOF MIL-100(Cr) [78]) could be reflected in augmented NOC adsorption. Similar results (augmented IND and QUI adsorption) were reported [79] after modifying MIL-101(Cr) by adenine, followed by protonation. However, the complexity of synthesis protocols of those functionalized materials could very probably make them non-scalable and too expensive for practical real world applications.

It is worth mentioning that the silica adsorbent used in the SK pretreatment process [80] was non-selective during NOC removal as interaction of those species with adsorbent was through hydrogen bonding due $\mathrm{SiO}_{2}$ surface lacking acidity. However, that characteristic could positively affect adsorbent regenerability due to weak NOC adsorption [80].

\subsection{Catalytic HDT of pristine and low-nitrogen real feedstocks}

Among tested streams SRGO2 and SR1LC must be the most difficult to hydrotreat due to their enhanced NOC content (Tab. 1). Also, their high $\mathrm{S}$ concentration and high-end boiling point (BP) could contribute to increased S-removal complexity as sterically hindered alkyl-DBT could be mainly in the $330-360{ }^{\circ} \mathrm{C}$ distillation fraction [10]. CGO could not significantly contribute in augmenting refractory $\mathrm{S}$ species in SR1LC mixture due to its final BP $\left(323^{\circ} \mathrm{C}\right)$.

HDS was dramatically improved by $74 \mathrm{wt} \% \mathrm{~N}$-removal from SRGO1 (LNSR1 stream, Tab. 3) where $\mathrm{S}$ in product decreased from 400 to $15 \mathrm{ppm}$ at operating temperature as low as $330^{\circ} \mathrm{C}$ (Fig. 6, see rest of conditions in captions).

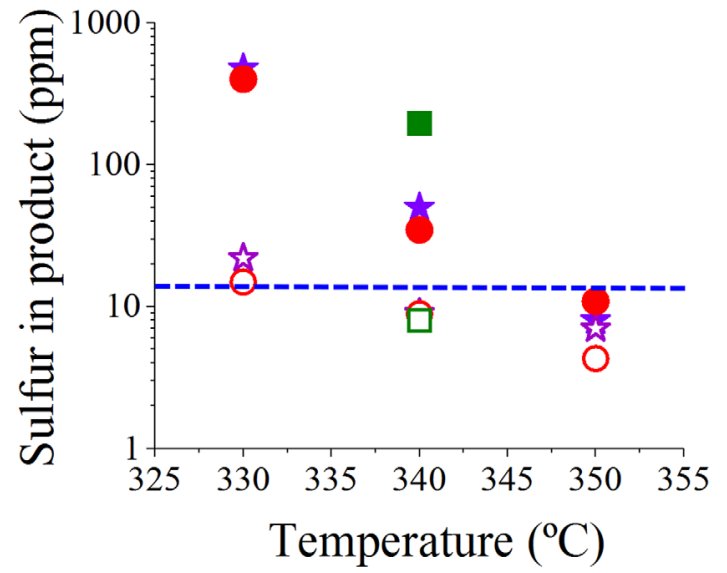

Fig. 6. Operating temperature effect on HDS by using pristine and corresponding LN feedstocks. $\bigcirc$ : SRGO1; $\bigcirc$ : LNSR1; $\square$ : SRGO2; $\square$ : LNSR2; $\star$ : SR1LC; $九$ : LNSR1LC. Dashed blue line represents ULSD limit $(\mathrm{S}<15 \mathrm{ppm})$. Up-flow steady-state fixed-bed reactor, $P=56 \mathrm{~kg} \mathrm{~cm}^{-2}(5.77 \mathrm{MPa}), \mathrm{LHSV}=1.5 \mathrm{~h}^{-1}$, $\mathrm{H}_{2} /$ oil $=2500 \mathrm{ft}^{3} \mathrm{bbl}^{-1}\left(445 \mathrm{~m}^{3} \mathrm{~m}^{-3}\right)$.

No lower operating temperature was tested due to exponential growth in S content in hydrotreated SRGO1 by strong inhibition from NOC which exothermal adsorption was favored at temperature $<330{ }^{\circ} \mathrm{C}$ [36]. Increasing temperature to $350{ }^{\circ} \mathrm{C}$ was required to produce ULSD $(\sim 11 \mathrm{ppm} \mathrm{S})$ under otherwise similar conditions when feedstock was pristine SRGO. Thus, $20{ }^{\circ} \mathrm{C}$ lower HDT temperature was required in obtaining ULSD when the LN stream was fed. Estimating $\sim 1{ }^{\circ} \mathrm{C}$ month $^{-1}$ deactivation [40] in industrial hydrotreaters (WABT must be increased by that amount to keep $\mathrm{S}$ isoconversion) $\sim 20$ months longer cycle length was suggested. Advantage in HDS performance by using LN feedstock (as to that when using the pristine stream) diminished as operating temperature increased because strongly exothermal NOC adsorption was unfavored at augmented severity [5] whereas HDN kinetics was enhanced. Producing ULSD ( $\sim 6 \mathrm{ppm} \mathrm{S})$ at $340{ }^{\circ} \mathrm{C}$ from pristine SRGO1 required enhanced (by $\sim 1.7$ factor) feedstock-catalyst contact time, as to that used when testing LNSR1 (Fig. 7). In real-world hydrotreaters that could mean significantly decreased ULSD production. Otherwise and to keep unaltered productivity, $70 \%$ additional reaction volume could be needed when using pristine feedstock, demanding for expensive plant revamp. Note that room to install a grassroots new reactor could be not available 


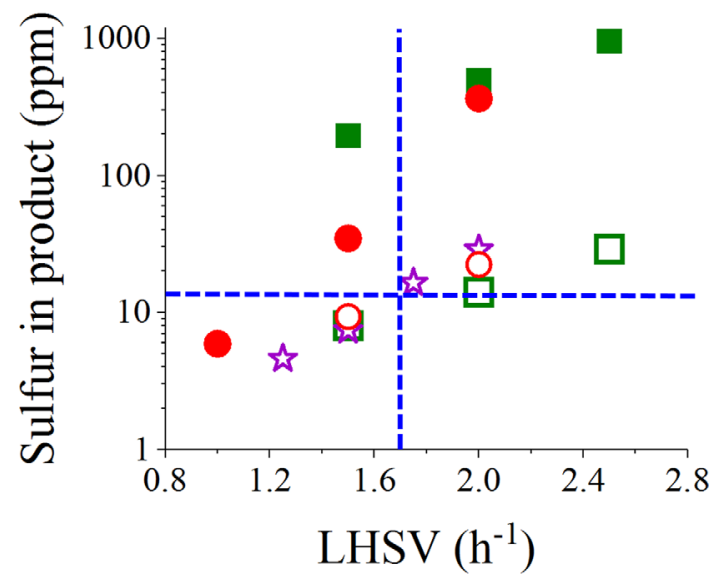

Fig. 7. LHSV effect on HDS by using pristine and corresponding LN feedstocks. O: SRGO1; O: LNSR1; $\square:$ SRGO2; $\square$ : LNSR2; t : LNSR1LC. Left-down quadrant (delimited by dashed blue lines) represents ULSD $(S<15 \mathrm{ppm})$ operating window. Up-flow steady-state fixed-bed reactor, $P=56 \mathrm{~kg} \mathrm{~cm}^{-2}(5.77 \mathrm{MPa})$, $T=340{ }^{\circ} \mathrm{C}, \mathrm{H}_{2} / \mathrm{oil}=2500 \mathrm{ft}^{3} \mathrm{bbl}^{-1}\left(445 \mathrm{~m}^{3} \mathrm{~m}^{-3}\right)$.

in most of refineries operating nowadays. Although temperature could be increased to produce ULSD that could significantly affect catalysts cycle life as enhanced severity could provoke accelerated deactivation by thermodynamics limitations (diminished adsorbed hydrogen and aromatics hydrogenation equilibrium conducting to polymerization on catalysts surface then coking [81]).

SRGO2 was a straight-run gas oil from different crude slates as to that from which SRGO1 was obtained, containing enhanced proportion of heavier oil. In spite of low initial boiling point, SRGO2 had significantly augmented total $\mathrm{S}$ and $\mathrm{N}$ concentration as to SRGO1. Then, some different $\mathrm{S}$ - and N-species in SRGO2 as to those in SRGO1 could be expected. Substantially higher S $(\sim 69 \%)$ and N-content $(\sim 86 \%)$ in SRGO2 as to that of SRGO1 was reflected in lower desulfurization when operating under similar HDT conditions (Fig. 6). Again, advantage of using LN feedstock was evidenced as ULSD could be produced at $340{ }^{\circ} \mathrm{C}$ from LNSR2 (83 wt\% $\mathrm{N}$ removal, Tab. 3) even at LHSV $=2 \mathrm{~h}^{-1}$ (Fig. 7). It is worth nothing that regardless of the much higher S content in SRGO2 an important proportion of those sulfur-bearing species could be of enhanced reactivity to those in SRGO1. Due to its much lower initial boiling point $\left(161{ }^{\circ} \mathrm{C}\right.$, Tab. 1$)$ the former could comprise thiophene alkyl derivatives of considerably high reactivity [82, 83]. However, due to its very high $\mathrm{S}$ and $\mathrm{N}$ concentration, enabling ULSD production from SRGO2 could require prohibitively very low space velocity rendering the operation economically unfeasible (Fig. 7).

Regarding the LNSR1LC mixture (72.33 wt\% N removal as to the pristine SR1LC stream, Tab. 3), higher $\mathrm{S}$ in HDT product could be expected considering addition of less reactive cracked streams to SRGO1. High aromatics contents characterize LCO whereas augmented NOC concentration was present in CGO (Tab. 1). However, significant concentration of sterically hindered S species (boiling

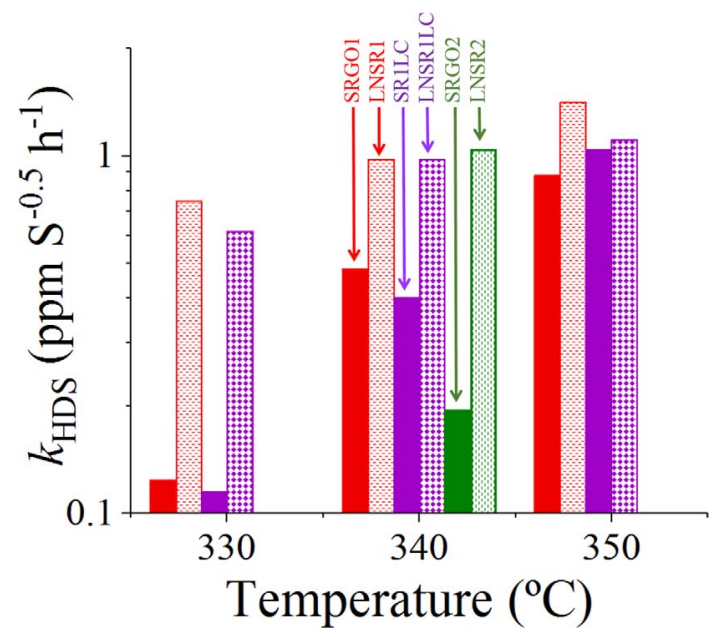

Fig. 8. Effect of temperature on HDS kinetic constants (reaction order $n=1.5$ ) determined from various tested pristine and corresponding LN feedstocks. $P=56 \mathrm{~kg} \mathrm{~cm}^{-2}(5.77 \mathrm{MPa})$, $\mathrm{LHSV}=1.5 \mathrm{~h}^{-1}, \mathrm{H}_{2} /$ oil $=2500 \mathrm{ft}^{3} \mathrm{bbl}^{-1}\left(445 \mathrm{~m}^{3} \mathrm{~m}^{-3}\right)$.

point $\sim 365{ }^{\circ} \mathrm{C}$ ) could be discarded in those cracked feedstocks (especially in CGO) due to their final boiling point.

ULSD could not be produced by hydrotreating LNSR1LC at $330{ }^{\circ} \mathrm{C}$ (Fig. 6 , rest of operating parameters in corresponding captions). At $340{ }^{\circ} \mathrm{C}, \sim 9 \mathrm{ppm} \mathrm{S}$ in product were obtained. Thus, and in agreement with others [37] it seemed that the beneficial effect of NOC removal on HDT was even more notable when heavier feedstocks of higher aromatics content as LCO of significantly lower -API gravity as to that of SRGO1 (13.4 and 33.4, respectively, Tab. 1) were added. At $350{ }^{\circ} \mathrm{C}$ and similarly to the case of SRGO1 (pristine and LN) ULSD (7-8 ppm S) was obtained by using both mixed feedstocks (pristine and corresponding pretreated stream). Clearly, at those conditions the high NOC content of SR1LC did not exert strong inhibition because of diminished NOC exothermal adsorption and accelerated HDN kinetics due to the highly active catalytic formulation used. Aleksandrov et al. [84] found that Light Coker Gas Oil (LCGO) addition to SRGO was reflected in increased $\mathrm{S}$ in product when operating at $350{ }^{\circ} \mathrm{C}$. However and in spite of enhanced NOC content ( $45 \%$ higher) in the mixture with 15 wt\% LCGO, by augmenting temperature to $365{ }^{\circ} \mathrm{C}$ sulfur in product was slightly lower to that in hydrotreated SRGO. Thus, ULSD $\left(10 \mathrm{ppm}\right.$ ) could be produced (at LHSV $=0.9 \mathrm{~h}^{-1}, P=3.5$ MPa and $\mathrm{H}_{2} /$ oil $=300 \mathrm{~m}^{3} \mathrm{~m}^{-3}$ ) by using either feedstock.

Cracked cheaper streams addition to SRGO1 then submitted to NOC removal (LNSR1LC) resulted in minimal variation on $\mathrm{S}$ in HDT product, as to that from LNSR1, in the temperature range studied (Fig. 6) and at all the tested LHSV values (Fig. 7) as well.

From HDS data obtained kinetic parameters (reaction order $n$, kinetic constants at various temperatures (from Eq. (1)) and corresponding activation energy values were calculated (Fig. 8 and Tab. 4). For SRGO (both pristine and LN) the best fit for linear regression of equation (1) 
Table 4. HDS reaction order ( $n$, from best fit of Eq. (1)) for various tested pristine and LN middle distillates. Activation energy $\left(E_{a}\right)$ as determined from corresponding Arrhenius plots also included. Steady-state up-flow fixed-bed reactor, $T=330-350{ }^{\circ} \mathrm{C}, P=56 \mathrm{~kg} \mathrm{~cm}^{-2}(5.77 \mathrm{MPa}), \mathrm{LHSV}=1.25-2.5 \mathrm{~h}^{-1}, \mathrm{H}_{2} / \mathrm{oil}=2500 \mathrm{p}^{3} \mathrm{bbl}^{-1}\left(445 \mathrm{~m}^{3} \mathrm{~m}^{-3}\right)$.

\begin{tabular}{|c|c|c|c|c|c|c|}
\hline Stream & SRGO1 & LNSR1 & SRGO2 & LNSR2 & SR1LC & LNSR1LC \\
\hline$n$ & 1.5 & 1.5 & 1.5 & 1.5 & ND & 1.5 \\
\hline$R$-squared ${ }^{\mathrm{a}}$ & 0.999 & 1 & 0.996 & 0.984 & $\mathrm{ND}$ & 0.9875 \\
\hline$E_{a}\left(\mathrm{~kJ} \mathrm{~mol}^{-1}\right)$ & 94.58 & 30.45 & ND & ND & 105.6 & 28.36 \\
\hline
\end{tabular}

${ }^{\mathrm{a}}$ From least squares linear regression.

was $n=1.5$ HDS reaction order whereas for LNSR1LC it corresponded to $n=1.75$. Reaction order could be increased in heavier middle distillates HDS as to that of lighter ones [85] due to kinetics of more complex compounds [86]. Although $n=1.75$ reaction order was the best fitted for LNSR1LC data $(R$-squared $=0.9915), n=1.5$ also provided very good data correlation $(R$-squared $=0.9875)$. Then, given the strong dependence of kinetic constants respecting $n$ (Eq. (1)), to make them comparable one to another, 1.5 reactor order was used for all tested feedstocks (Tab. 4).

By removing $74 \mathrm{wt} \%$ of NOC from SRGO1 $k_{\mathrm{HDS}}$ (at $330^{\circ} \mathrm{C}$ ) was increased by a factor of 6 (Fig. 8). However, at $350{ }^{\circ} \mathrm{C}$ the advantage of LNSR1 as feedstock (instead of pristine SRGO1) diminished to $61 \%$ due to more favored HDN kinetics and lower NOC inhibition under more severe conditions [5]. The general trend was similar for the pristine mixture (SR1LC) and corresponding LN stream although in this case $k_{\mathrm{HDS}}$ (at $330{ }^{\circ} \mathrm{C}$ ) were lower as to those of SRGO1 and LNSR1, respectively, probably due to enhanced inhibition from significantly higher NOC amount (36 and 46\%, for SR1LC and LNSR1LC, respectively, Tab. 3). At $340{ }^{\circ} \mathrm{C}$, SRGO2 had the lowest $k_{\text {HDS }}$ that could be caused by its considerable $\mathrm{S}$ and $\mathrm{N}$ content. However, the corresponding LN feedstock had 5.4-fold increased $k_{\mathrm{HDS}}$ (as to that corresponding to the pristine untreated feedstock) due to less inhibited reaction sites.

From corresponding Arrhenius plots (not shown) HDS activation energy $\left(E_{a}\right)$ for various tested middle distillates was determined, Table 4. Value for pristine stream SRGO1 was similar to those reported elsewhere for middle distillates HDT $[85,86]$. Enhanced $E_{a}$ for non-treated SR1LC mixture as to that found for SRGO1 was consistent with the stronger inhibition exerted by its higher NOC content [86, 87]. By increasing operating temperature NOC desorption and HDS and HDN reactions kinetics were favored that being reflected in enhanced desulfurization activity response at more severe conditions (thus, augmented $E_{a}$ ).

Regarding low $E_{a}$ values for LN feedstocks HDS the effect of diffusional limitations could not be discarded. Indeed, $E_{a}$ values below $41.8 \mathrm{~kJ} \mathrm{~mol}^{-1}$ are generally considered as evidence of reaction control by diffusional phenomena $[88,89]$. Even at the lowest tested temperature $\left(330^{\circ} \mathrm{C}\right)$ very high S-bearing species conversion was observed for LN feedstocks (Fig. 6) which could lead to S conversion controlled by the limited reactants availability when testing at more severe conditions.

Finally, the effectivity of our process comprising extruded MIL-101(Cr) as NOC removal adsorbent (loaded in fixed-bed column) from oil-derived middle distillates has been clearly demonstrated. Although others [80] have claimed successful NOC removal from hydrocarbon streams using silica-gel/ion exchange resin combination no shaped adsorbents were mentioned but just small particles (0.3$1 \mathrm{~mm}$ ). In our case, extrudates utilizations make our process attractive in real-world applications as pretreatment of feedstocks for ULSD production. By significantly increasing cycle life of HDS catalytic formulations frequency of expensive turnarounds (750 000-1 000000 US dollars day ${ }^{-1}$, 3-4 weeks [90]) for catalysts change could be substantially reduced.

Encouraging results obtained during ULSD production by using LN pretreated feedstocks HDT have been confirmed in a larger pilot plant $\left(100 \times 10^{-6} \mathrm{~m}^{3}\right)$ loaded with commercial size extruded catalyst operating under HDT conditions relevant to industrial facilities in Mexican refineries. Our patented technology $[41,50]$ is presently in scaling-up stage.

\section{Conclusion}

Highly crystalline MIL-101(Cr) metal-organic framework was prepared with propylene oxide as proton scavenger that resulting in adsorbent of improved mesoporosity and essentially unaltered surface and structural properties. Nitrogen Organic Compounds (NOC) selective adsorption (over those of S-bearing species and aromatics) was carried out as pre-treatment of various oil-derived middle distillates aimed to ultra-low sulfur production (ULSD, $\mathrm{S} \leq 15 \mathrm{ppm}$ ) under pilot plant at operating conditions relevant to industrial HyDroTreating (HDT). NOC removal was carried out at mild conditions (room temperature and atmospheric pressure), the solid being easily regenerable by $n$-hexane and acetone washing at mild conditions. Extruded MIL-101(Cr) ( $\left.1800 \mathrm{~m}^{2} \mathrm{~g}^{-1}\right)$ efficiently removed NOC from oil-derived real feedstocks to concentrations $\sim 80 \mathrm{ppm}$ (from 220-400 ppm in non-pretreated streams) which allowed ULSD production at much milder conditions as to those used during pristine hydrocarbon feedstocks HDT. Thus, operating temperature could be significantly diminished (from 350 to $330{ }^{\circ} \mathrm{C}$ ), during straight-run gas oil HDT (at $56 \mathrm{~kg} \mathrm{~cm}^{-2}(5.77 \mathrm{MPa}), \mathrm{LHSV}=1.5 \mathrm{~h}^{-1}$ and $\mathrm{H}_{2} /$ oil $=$ $\left.2500 \mathrm{ft}^{3} \mathrm{bbl}^{-1}\left(445 \mathrm{~m}^{3} \mathrm{~m}^{-3}\right)\right)$ which could significantly prolong cycle life of commercial sulfided $\mathrm{NiMo} / \mathrm{Al}_{2} \mathrm{O}_{3}$ formulations. That could be reflected in less frequent expensive turn-arounds for spent catalysts change in commercial-scale 
hydrotreaters, with consequential improved revenues for the refiner while producing on-spec ULSD.

\section{Supplementary materials}

Supplementary material is available at https://ogst. ifpenergiesnouvelles.fr/10.2516/ogst/2021038/olm

Figure S1. Scheme of the NOC (from real feedstocks, oil-derived middle distillates) adsorption system used. Packed bed (MIL-101(Cr) extrudates) operating at room temperature, atmospheric pressure $(78 \mathrm{kPa})$ and LHSV $=$ $0.6-1.5 \mathrm{~h}^{-1}$

Figure S2. $\mathrm{N}_{2}$ physisorption isotherm $\left(-198^{\circ} \mathrm{C}\right)$ of asprepared MOF MIL-101(Cr) synthesized with propylene oxide as proton scavenger. Filled squares: Adsorption branch; Open squares: Desorption branch.

Figure S3. X-ray diffraction pattern of as-prepared MOF MIL-101(Cr) synthesized with propylene oxide as proton scavenger.

Figure S4. Thermogravimetrical (a) and differential thermogravimetrical (b) profiles of prepared MIL-101(Cr) extrudates.

Figure S5. UV-vis spectrum of extruded adsorbent MIL-101(Cr) prepared with propylene oxide.

Figure S6. Infrared spectrum of extruded adsorbent MIL-101(Cr) prepared with propylene oxide.

Figure S\%. Raman spectra of various analyzed zones of extruded adsorbent MIL-101(Cr) prepared with propylene oxide.

Figure S8. SEM micrographs of extruded MOF MIL-101(Cr) material at various magnifications. (a) $200 \times$; (b) $2000 \times$; (c) $100000 \times$; (d) $120000 \times$.

Acknowledgments. Authors acknowledge SENER-CONACYTHIDROCARBUROS fund and IMP for support of the investigation through Y.00117 and D.61051 grants, respectively. The authors also acknowledge questions and comments from anonymous reviewers that strongly contributed in improving the quality of this paper. Technical contribution (materials characterization) by colleagues from academia ( $U V, U A E M$ and $I N I N)$ is gratefully appreciated by IMP authors as well.

\section{References}

1 Cheng Y., Montreuil C., Cavataio G., Lambert C. (2009) Sulfur tolerance and $\mathrm{DeSO}_{\mathrm{x}}$ studies on diesel SCR catalysts, SAE Int. J. Fuels Lubr. 1, 1, 471-476. https://doi.org/ 10.4271/2008-01-1023.

2 Bataille F., Lemberton J.L., Michaud P., Pérot G., Vrinat M., Lemaire M., Schulz E., Breysse M., Kasztelan S. (2000) Alkyldibenzothiophenes hydrodesulfurization-promoter effect, reactivity, and reaction mechanism, J. Catal. 191, 409-422. https://doi.org/10.1006/jcat.1999.2790.

3 Choi K., Korai Y., Mochida I., Ryu J.W., Min W. (2004) Impact of removal extent of nitrogen species in gas oil on its HDS performance: An efficient approach to its ultra deep desulfurization, Appl. Catal. B-Environ. 50, 9-16. https://doi. org/10.1016/j.apcatb.2003.10.011.
4 Girgis M.J., Gates B.C. (1991) Reactivities, reaction networks, and kinetics in high-pressure catalytic hydroprocessing, Ind. Eng. Chem. Res. 30, 2021-2058. https://doi.org/ 10.1021/ie00057a001.

5 Álvarez A., Escobar J., Toledo J.A., Pérez V., Cortés M.A., Pérez M., Rivera E. (2007) HDS of straight-run gas oil at various nitrogen contents. Comparison between different reaction systems, Fuel 86, 9, 1240-1246. https://doi.org/ 10.1016/j.fuel.2006.08.001.

6 Shen J., Semagina N. (2020) Inhibition of diolefin hydrogenation by quinoline, Energy Fuels 34, 7, 8769-8776. https://doi.org/10.1021/acs.energyfuels.0c01336.

7 Laveille P., Chaudhry A.-H., Riva A., Salameh A., Singaravel G., Dufresne P., Morin S., Berthod M. (2018) Maximizing utilization of reactivated and left-over catalysts in heavy gas oil hydrotreater: A case study of ADNOC refining, Oil Gas Sci. Technol. - Rev. IFP Energies nouvelles 73, 59, 1-10. https://doi.org/10.2516/ogst/2018053.

8 Lehr M., Ohms R. (2016) Impact of Light Tight oils on Distillate Hydrotreater Operation, in: Processing Shale Feedstocks 2016, pp. 1-10. https:/ / www.digitalrefining.com/article/ 1001241.

9 Yang H., Chen J., Fairbridge C., Briker Y., Zhu Y.J., Ring Z. (2004) Inhibition of nitrogen compounds on the hydrodesulfurization of substituted dibenzothiophenes in light cycle oil, Fuel Process Technol. 85, 1415-1429. https://doi.org/ 10.1016/j.fuproc.2003.09.008.

10 Al-Barood A., Stanislaus A. (2007) Ultra-deep desulfurization of coker and straight-run gas oils: Effect of lowering feedstock 95\% boiling point, Fuel Process Technol. 88, 309-315. https://doi.org/10.1016/j.fuproc.2006.10.008.

11 Prado G.H.C., Rao Y., de Klerk A. (2017) Nitrogen removal from oil: A review, Energy Fuels 31, 14-36. https://doi.org/ 10.1021/acs.energyfuels.6b02779.

12 LaVopa V., Satterfield C.N. (1988) Poisoning of thiophene hydrodesulfurization by nitrogen compounds, J. Catal. 110, 375-387. https://doi.org/10.1016/0021-9517(88)90328-4.

13 Kaluža L., Gulková D., Šolcová O., Žilková N., Čejka J. (2008) Hydrotreating catalysts supported on organized mesoporous alumina: Optimization of Mo deposition and promotional effects of $\mathrm{Co}$ and Ni, Appl. Catal. A-Gen. 351, 93-101. https://doi.org/10.1016/j.apcata.2008.09.002.

14 Prada Silvy R., Lageshetty S.K. (2021) Conversion of heavy gasoil into ultra-low sulfur and aromatic diesel over $\mathrm{NiWRu}$ / $\mathrm{TiO}_{2}-\gamma \mathrm{Al}_{2} \mathrm{O}_{3}$ catalysts: Role of titanium and ruthenium on improving catalytic activity, Oil Gas Sci. Technol. - Rev. IFP Energies nouvelles 76, 5, 1-19. https://doi.org/10.2516/ ogst/2020084.

15 Kaluža L. (2015) Activity of transition metal sulfides supported on $\mathrm{Al}_{2} \mathrm{O}_{3}, \mathrm{TiO}_{2}$ and $\mathrm{ZrO}_{2}$ in the parallel hydrodesulfurization of 1-benzothiophene and hydrogenation of 1-methyl-cyclohex-1-ene, Reac. Kinet. Mech. Cat. 114, 781-794. https://doi.org/10.1007/s11144-014-0809-9.

16 Liu D., Gui J., Sun Z. (2008) Adsorption structures of heterocyclic nitrogen compounds over $\mathrm{Cu}(\mathrm{I}) \mathrm{Y}$ zeolite: A first principle study on mechanism of the denitrogenation and the effect of nitrogen compounds on adsorptive desulfurization, J. Mol. Catal. A-Chem. 291, 1-2, 17-21. https://doi.org/ 10.1016/j.molcata.2008.05.014.

17 Sano Y., Choi K., Korai Y., Mochida I. (2004) Adsorptive removal of sulfur and nitrogen species from a straight run gas oil over activated carbons for its deep HDS, Appl. Catal. B-Environ. 49, 4, 219-225. https://doi.org/10.1016/j.apcatb.2003.12.007. 
18 Li Z., Liang H., Li X., Yang C., Ge B., Xiong S., Zhang H., Wang T., Yuan P. (2020) Adjusting surface acidity of hollow mesoporous carbon nanospheres for enhanced adsorptive denitrogenation of fuels, Chem. Eng. Sci. 228, 115963, 1-11. https://doi.org/10.1016/j.ces.2020.115963.

19 Li H., Eddaoudi M., O'Keeffe M., Yaghi O.M. (1999) Design and synthesis of an exceptionally stable and highly porous metal-organic framework, Nature 402, 276-279. https: / doi. org $/ 10.1038 / 46248$.

20 Yin D., Li C., Ren H., Shekhah O., Liu J., Liang C. (2017) Efficient Pd@MIL-101(Cr) hetero-catalysts for 2-butyne-1, 4-diol hydrogenation exhibiting high selectivity, $R S C A d v$. 7, 1626-1633. https://doi.org/10.1039/c6ra25722d.

21 Xu Y., Lv M., Yang H., Chen Q., Liu X., Wei F. (2015) $\mathrm{BiVO}_{4} / \mathrm{MIL}-101$ composite having the synergistically enhanced visible light photocatalytic activity, $R S C A d v .5$, 43473-43479. https://doi.org/10.1039/C4RA11383G.

22 Liu Q., Ning L., Zheng S., Tao M., Shi Y., He Y. (2016) Adsorption of carbon dioxide by MIL-101(Cr): Regeneration conditions and influence of flue gas contaminants, Sci. Rep. 3, 2916, 1-6. https://doi.org/10.1038/srep02916.

23 Chen M.-L., Zhou S.-Y., Xu Z., Ding L., Cheng Y.-H. (2019) Metal-organic frameworks of MIL-100(Fe, Cr) and MIL$101(\mathrm{Cr})$ for aromatic amines adsorption from aqueous solutions, Molecules 24, 3718, 1-13. https://doi.org/10.3390/ molecules24203718.

24 Bhattacharjee S., Chena C., Ahn W.-S. (2014) Chromium terephthalate metal-organic framework MIL-101: synthesis, functionalization, and applications for adsorption and catalysis, $R S C A d v$. 4, 52500-52525. https://doi.org/10.1039/ c4ra11259h.

25 Abedini H., Shariati A., Khosravi-Nikou M.R. (2020) Separation of propane/propylene mixture using MIL-101(Cr) loaded with cuprous oxide nanoparticles: Adsorption equilibria and kinetics study, Chem. Eng. J. 387, 124172, 1-10. https://doi.org/10.1016/j.cej.2020.124172.

26 Chen Q., Wang M.-M., Hu X., Chen X.-W., Wang J.-H. (2016) An octamolybdate-metal organic framework hybrid for the efficient adsorption of Histidine-rich proteins, $J$. Mater. Chem. B 42, 6812-6819. https://doi.org/10.1039/ C6TB02090A.

27 Suresh M., Raju B.D., Rao K.S.R., Reddy K.R., Kantam M. L., Srinivasu P. (2014) Metal organic framework MIL-101 (Cr) for dehydration reactions, J. Chem. Sci. 126, 527-532. https://doi.org/10.1007/s12039-014-0590-3.

28 Akimana E., Wang J., Likhanova N.V., Chaemchuen S., Verpoort F. (2020) MIL-101(Cr) for $\mathrm{CO}_{2}$ conversion into cyclic carbonates, under solvent and co-catalyst free mild reaction conditions, Catalysts 10, 453, 1-11. https://doi.org/ 10.3390/catal10040453.

29 Khan N.A., Jhung S.H. (2019) Phytic acid-encapsulated MIL-101(Cr): Remarkable adsorbent for the removal of both neutral indole and basic quinoline from model liquid fuel, Chem. Eng. J. 375, 121948, 1-8. https://doi.org/10.1016/j. cej.2019.121948.

30 Mondol MdMH, Bhadra B.N., Park J.M., Jhung S.H. (2020) A remarkable adsorbent for removal of nitrogenous compounds from fuel: a metal-organic framework functionalized both on metal and ligand, Chem. Eng. J. 404, 126491, 1-9. https://doi.org/10.1016/j.cej.2020.126491.

31 Nuzhdin A.L., Kovalenko K.A., Dybtsev D.N., Bukhtiyarova G.A. (2010) Removal of nitrogen compounds from liquid hydrocarbon streams by selective sorption on metal-organic framework MIL-101, Mendeleev Commun. 20, 1, 57-58. https://doi.org/10.1016/j.mencom.2010.01.022.

32 Maes M., Trekels M., Boulhout M., Schouteden S., Vermoortele F., Alaerts L., Heurtaux D., Seo Y.-K., Hwang Y.K., Chang J.-S., Beurroies I., Denoyel R., Temst K., Vantomme A., Horcajada P., Serre C., De Vos D.E. (2011) Selective removal of N-heterocyclic aromatic contaminants from fuels by Lewis acidic metal-organic frameworks, Angew. Chem. Int. Ed. 50, 4210-4214. https://doi.org/10.1002/ anie.201100050.

33 Kim M.J., Park S.M., Song S.-J., Won J., Lee J.Y., Yoon M., Kim K., Seo G. (2011) Adsorption of pyridine onto the metal organic framework MIL-101, J. Colloid Interface Sci. 361, 612-617. https://doi.org/10.1016/j.jcis.2011.05.067.

34 Pearson R.G. (1963) Hard and soft acids and bases, J. Am. Chem. Soc. 85, 3533-3539. https://doi.org/10.1021/ja00905a001.

35 Laredo G.C., Vega-Merino P.M., Montoya-de la Fuente J.A., Mora-Vallejo R.J., Meneses-Ruiz E., Castillo J.J., ZapataRendón B. (2016) Comparison of the metal-organic framework MIL-101 (Cr) versus four commercial adsorbents for nitrogen compounds removal in diesel feedstocks, Fuel 180, 284-291. https://doi.org/10.1016/j.fuel.2016.04.038.

36 Min W. (2002) A unique way to make ultra low sulfur diesel, Korean J. Chem. Eng. 19, 4, 601-606. https://doi.org/ 10.1007/BF02699303.

37 Lee S.-W., Ryu J.W., Min W. (2003) SK hydrodesulfurization (HDS) pretreatment technology for ultralow sulfur diesel (ULSD) production, Catal. Surv. Asia 7, 4, 271-279. https://doi.org/10.1023/B:CATS.0000008166.74672.db.

38 Hoekstra G. (2019) Real-world catalysts testing, 2019, in: Digital Refining, July 2019, pp. 1-6. https://www.digitalrefining.com/article/1002339.

39 Stefanidis G.D., Bellos G.D., Papayannakos N.G. (2005) An improved weighted average reactor temperature estimation for simulation of adiabatic industrial hydrotreaters, Fuel Process Technol. 86, 1761-1775. https://doi.org/10.1016/ j.fuproc.2005.04.002.

40 Fujikawa T., Chiyoda O., Tsukagoshi M., Idei K., Takehara S. (1998) Development of a high activity HDS catalyst for diesel fuel: From basic research to commercial experience, Catal. Today 45, 307-312. https://doi.org/10.1016/S09205861(98)00235-1.

41 Mora R.J., Montoya J.A., Laredo G.C., Meneses E., Castillo J.J., Zapata B. (2016) Process for reducing the content of organic nitrogen compounds from hydrotreating feedstocks for ultra-low sulfur production, US Patent 2016/0332138A1.

42 Hong W.Y., Perera S.P., Burrows A.D. (2015) Manufacturing of metal-organic framework monoliths and their application in $\mathrm{CO}_{2}$ adsorption, Micropor. Mesopor. Mater. 214, 149-155. https://doi.org/10.1016/j.micromeso.2015.05.014.

43 Hong W.Y., Perera S.P., Burrows A.D. (2020) Comparison of MIL-101(Cr) metal-organic framework and 13X zeolite monoliths for $\mathrm{CO}_{2}$ capture, Micropor. Mesopor. Mater. 308, 110525, 1-9. https://doi.org/10.1016/j.micromeso.2020. 110525.

44 Zeuthen P. (2019) A new generation of catalyst is born: TK6001 HySwell, pp. 1-2. https://www.digitalrefining.com/ article/1002269.

45 Arandes J.M., Torre I., Azkoiti M.J., Ereña J., Bilbao J. (2008) Effect of atmospheric residue incorporation in the Fluidized Catalytic Cracking (FCC) feed on product stream yields and composition, Energy Fuels 22, 2149-2156. https://doi.org/10.1021/ef800031x. 
46 Jeon H.-R., Kim K.-D., Lee Y.-K. (2020) Highly active and stable $\mathrm{MoWS}_{2}$ catalysts in slurry phase hydrocracking of vacuum residue, J. Catal. 390, 117-125. https://doi.org/ 10.1016/j.jcat.2020.07.009.

47 Ramírez L.F., Escobar J., Galván E., Vaca H., Murrieta F., Luna M.R.S. (2004) Evaluation of diluted and undiluted trickle-bed hydrotreating reactor with different catalyst volume, Pet. Sci. Technol. 22, 1-2, 157-175. https://doi. org/10.1081/LFT-120028530.

48 Sau M., Basak K., Manna U., Santra M., Verma R.P. (2006) Effects of organic nitrogen compounds on hydrotreating and hydrocracking reactions, Catal. Today 109, 1-4, 112-119. https://doi.org/10.1016/j.cattod.2005.08.007.

49 Bej S.K., Dalai D.K., Adjaye J. (2002) Kinetics of hydrodesulfurization of heavy gas oil derived from oil-sands bitumen, Pet. Sci. Technol. 20, 867-877. https://doi.org/ 10.1081/LFT-120003718.

50 Mora R.J., Montoya J.A., Laredo G.C., Meneses E., Castillo J.J., Zapata B. (2017) Process for obtaining metal-organic materials with structure MIL- 101 (Cr) and MIL-101-Cr- $M^{x+}$, US Patent 2017/9,777,029 B2.

51 Hao S.Z., Liu H., Guo B., Li H., Zhang J., Gan L., Xu Z., Chen L. (2007) Sol-gel synthesis of alumina using inorganic salt precursor, Acta Phys.-Chim. Sin. 23, 3, 289-294.

52 Anastasova E.I., Ivanovski V., Fakhardo A.F., Lepeshkin A.I., Omar S., Drozdov A.S., Vinogradov V.V. (2017) A pure magnetite hydrogel: Synthesis, properties and possible applications, Soft Matter 13, 8651-8660. https://doi.org/10.1039/ c7sm01702b.

53 Myadam N.L., Nadargi D.Y., Gurav Nadargi J.D., Shaikh F.I., Chaskar M.G. (2020) A facile approach of developing $\mathrm{Al} /$ $\mathrm{SnO}_{2}$ xerogels via epoxide assisted gelation: A highly versatile route for formaldehyde gas sensors, Inorg. Chem. Commun. 116, 107901, 1-9. https://doi.org/10.1016/j.inoche.2020.107901.

54 Du P.D., Thanh H.T.M., To T.C., Thang H.S., Tinh M.X., Tuyen T.N., Hoa T.T., Khieu D.Q. (2019) Metal-organic framework MIL-101: Synthesis and photocatalytic degradation of Remazol Black B Dye, J. Nanomater. 6061275, 1-15. https://doi.org/10.1155/2019/6061275.

55 Huang X.-X., Qiu L.-G., Zhang W., Yuan Y.P., Jiang X., Xie A.-J., Shen Y.H., Zhu J.-F. (2012) Hierarchically mesostructured MIL-101 metal-organic frameworks: Supramolecular template-directed synthesis and accelerated adsorption kinetics for dye removal, CrystEngComm 14, 1613-1617. https://doi.org/10.1039/c1ce06138k.

56 Liu S., Xu F., Liu L.-T., Zhou Y.-L., Zhao W.-X. (2017) Heat capacities and thermodynamic properties of Cr-MIL-101, J. Therm. Anal. Calorim. 129, 509-514. https://doi.org/ 10.1007/s10973-017-6168-9.

57 Leng K., Sun Y., Li X., Sun S., Xu W. (2016) Rapid Synthesis of metal-organic frameworks MIL-101(Cr) without the addition of solvent and hydrofluoric acid, Cryst. Growth Des. 16, 1168-1171. https://doi.org/10.1021/acs.cgd.5b01696.

58 Weckhuysen B.M., Verberckmoes A.A., Baets A.R.D., Schoonheydt R.A. (1997) Diffuse reflectance spectroscopy of supported chromium oxide catalysts: A self-modeling mixture analysis, J. Catal. 166, 160-171. https://doi.org/ 10.1006/jcat.1997.1518.

59 Rivera-Torrente M., Pletcher P.D., Jongkind M.K., Nikolopoulos N., Weckhuysen B.M. (2019) Ethylene polymerization over metal-organic framework crystallites and the influence of linkers on their fracturing process, ACS Catal. 9, 3059-3069. https://doi.org/10.1021/acscatal.9b00150.
60 Qiu S., Wang Y., Wan J., Han J., Ma Y., Wang S. (2020) Enhancing water stability of MIL-101(Cr) by doping Ni(II), Appl. Surf. Sci. 525, 146511, 1-7. https://doi.org/10.1016/j. apsusc.2020.146511.

61 Sievers R.E., Bailar J.C. Jr (1962) Some metal chelates of ethylenediaminetetraacetic acid, diethylenetriaminepentaacetic acid, and triethylenetetraminehexaacetic acid, Inorg. Chem. 1, 174-182. https://doi.org/10.1021/ic50001a035.

62 Kayal S., Chakraborty A. (2018) Activated carbon (type Maxsorb-III) and MIL-101(Cr) metal organic framework based composite adsorbent for higher $\mathrm{CH}_{4}$ storage and $\mathrm{CO}_{2}$ capture, Chem. Eng. J. 334, 780-788. https://doi.org/ 10.1016/j.cej.2017.10.080.

63 Elsayed E., Anderson P., Al-Dadah R., Mahmoud S., Elsayed A. (2019) MIL-101(Cr)/calcium chloride composites for enhanced adsorption cooling and water desalination, J. Solid State Chem. 277, 123-132. https://doi.org/10.1016/ j.jssc.2019.05.026.

64 Zhao T., Li S.-H., Shen L., Wang Y., Yang X.-Y. (2018) The sized controlled synthesis of MIL-101(Cr) with enhanced $\mathrm{CO}_{2}$ adsorption property, Inorg. Chem. Commun. 96, 47-51. https://doi.org/10.1016/j.inoche.2018.07.036.

65 Kayal S., Sun B., Chakraborty A. (2015) Study of metalorganic framework MIL-101(Cr) for natural gas (methane) storage and compare with other MOFs (metal-organic frameworks), Energy 91, 772-781. https://doi.org/10.1016/ j.energy.2015.08.096.

66 Zhao H., Li Q., Wang Z., Wu T., Zhang M. (2020) Synthesis of MIL-101(Cr) and its water adsorption performance, Micropor. Mesopor. Mater. 297, 110044, 1-7. https://doi. org/10.1016/j.micromeso.2020.110044.

67 Wang S., Bromberg L., Schreuder-Gibson H., Hatton T.A. (2013) organophophorous ester degradation by chromium (III) terephthalate metal-organic framework (MIL-101) chelated to $\mathrm{N}, \mathrm{N}$-dimethylaminopyridine and related aminopyridines, ACS Appl. Mater. Interf. 5, 4, 1269-1278. https: / /doi.org/10.1021/am302359b.

68 Jhung S.H., Lee J.H., Yoon J.W., Serre C., Férey G., Chang J.S. (2020) Microwave synthesis of chromium terephthalate MIL-101 and its benzene sorption ability, Adv. Mater. 19, 121-124. https://doi.org/10.1002/adma.200601604.

69 Laredo G.C., Leyva S., Alvarez R., Mares M.T., Castillo J., Cano J.L. (2002) Nitrogen compounds characterization in atmospheric gas oil and light cycle oil from a blend of Mexican crudes, Fuel 81, 10, 1341-1350. https://doi.org/ 10.1016/S0016-2361(02)00047-9.

70 Zhang H., Song H. (2012) Study of adsorptive denitrogenation of diesel fuel over mesoporous molecular sieves based on breakthrough curves, Ind. Eng. Chem. Res. 51, 49, 1605916065. https://doi.org/10.1021/ie302169r.

71 Dichiara A.B., Weinstein S., Rogers R.E. (2015) On the choice of batch or fixed-bed adsorption processes for wastewater treatment, Ind. Eng. Chem. Res. 54, 34, 85798586. https://doi.org/10.1021/acs.iecr.5b02350.

72 García-Gutiérrez J.L., Laredo G.C., Fuentes G.A., GarcíaGutiérrez P., Jiménez-Cruz F. (2014) Effect of nitrogen compounds in the hydrodesulfurization of straight-run gas oil using a $\mathrm{CoMoP} / \gamma-\mathrm{Al}_{2} \mathrm{O}_{3}$ catalyst, Fuel 138, 98-103. https://doi.org/10.1016/j.fuel.2014.08.008.

73 Wang Z., Sun Z., Kong L., Li G. (2013) Adsorptive removal of nitrogen-containing compounds from fuel by metalorganic frameworks, J. Energy Chem. 22, 869-875. https://doi.org/10.1016/S2095-4956(14)60266-7. 
74 Dorbon M., Bernasconi C. (1989) Nitrogen compounds in light cycle oils: identification and consequences of ageing, Fuel 68, 8, 1067-1074. https://doi.org/10.1016/0016-2361 (89)90077-X.

75 Shi Q., Xu C., Zhao S., Chung K.H., Zhang Y., Gao W. (2010) Characterization of basic nitrogen species in coker gas oils by positive-ion electrospray ionization Fourier Transform ion cyclotron resonance mass spectrometry, Energy Fuels 24, 1, 563-569. https://doi.org/10.1021/ef9008983.

76 Xiaobo C., Yibin L., Jin W., Honghong S., Chaohe Y., Chunyi L. (2014) Characterization of nitrogen compounds in coker gas oil by electrospray ionization Fourier transform ion cyclotron resonance mass spectrometry and Fourier transform infrared spectroscopy, Appl. Petrochem. Res. 4, 4, 417-422. https://doi.org/10.1007/s13203-014-0083-9.

77 Ahmed I., Khan N.A., Jhung S.H. (2013) Graphite oxide/ metal-organic framework (MIL-101): Remarkable performance in the adsorptive denitrogenation of model fuels, Inorg. Chem. 52, 14155-14161. https://doi.org/10.1021/ ic402012d.

78 Ahmed I., Hasan Z., Khan N.A., Jhung S.H. (2013) Adsorptive denitrogenation of model fuels with porous metal-organic frameworks (MOFs): Effect of acidity and basicity of MOFs, Appl. Catal. B-Environ. 129, 123-129. https://doi.org/10.1016/j.apcatb.2012.09.020.

79 Sarker M., Song J.Y., Jeong A.R., Min K.S., Jhung S.H. (2018) Adsorptive removal of indole and quinoline from model fuel using adenine-grafted metal-organic frameworks, J. Hazard. Mat. 355, 593-601. https://doi.org/10.1016/ j.jhazmat.2017.10.041.

80 Min S., Choi K.-I., Khang S.Y., Min D.-S., Ryu J.-W., Yoo K.S., Kim J.-H. (2001) Method for manufacturing cleaner fuels, US Patent 6,248,230 B1.

81 Bandyopadhyay R., Upadhyayula S. (2018) Thermodynamic analysis of diesel hydrotreating reactions, Fuel 214, 15, 314-321. https://doi.org/10.1016/j.fuel.2017.10.015.
82 Escobar J., Gutiérrez A., Barrera M.C., Colín J.A. (2016) NiMo/alumina hydrodesulfurization catalyst modified by saccharose. Effect of addition stage of organic modifier, Can. J. Chem. Eng. 94, 66-74. https://doi.org/10.1002/cjce.22334.

83 Song C. (2003) An overview of new approaches to deep desulfurization for ultra-clean gasoline, diesel fuel and jet fuel, Catal. Today 86, 1-4, 211-263. https://doi.org/ 10.1016/S0920-5861(03)00412-7.

84 Aleksandrov P.V., Bukhtiyarova G.A., Reshetnikov S.I. (2019) Study of the influence exerted by addition of coker gas oil to straight-run gas oil on the process of hydrotreating in the presence of $\mathrm{CoMo} / \mathrm{Al}_{2} \mathrm{O}_{3}$ catalyst, Russ. J. Appl. Chem. 92, 8, 1077-1083. https://doi.org/10.1134/S1070427219080044.

85 Ancheyta J., Angeles M.J., Macías M.J., Marroquín G., Morales R. (2002) Changes in apparent reaction order and activation energy in the hydrodesulfurization of real feedstocks, Energy Fuels 16, 1, 189-193. https://doi.org/ 10.1021/ef0101917.

86 Al-Barood A., Qabazard H., Stanislaus A. (2005) A comparative study of the HDS kinetics of straight run and coker gas oils under deep desulfurization conditions, Pet. Sci. Technol. 23, 7-8, 749-760. https://doi.org/10.1081/LFT-200031084.

87 Ferdous D., Dalai A.K., Adjaye J. (2005) Hydrodenitrogenation and hydrodesulphurization of heavy gas oil using $\mathrm{NiMo} / \mathrm{Al}_{2} \mathrm{O}_{3}$ catalyst containing phosphorus: Experimental and kinetic studies, Can. J. Chem. Eng. 83, 5, 855-864. https://doi.org/10.1002/cjce.5450830507.

88 Vrinat M.L. (1983) The kinetics of the hydrodesulfurization process - a review, Appl. Catal. 6, 2, 137-158. https://doi. org/10.1016/0166-9834(83)80260-7.

89 Louloudi A., Papayannakos N. (2016) Performance of Ni/Sipillared clay catalytic extrudates for benzene hydrogenation reaction, Appl. Clay Sci. 123, 47-55. https://doi.org/ 10.1016/j.clay.2015.12.034.

90 Williamson L. (2020) Effective preparation for turnarounds, in: Revamps, 2-10-2020, pp. 1-5. https://www.digitalrefining. com/magazines. 